INTERNATIONAL

FOOD POLICY

RESEARCH

INSTITUTE

IFPRI

IFPRI Discussion Paper 01940

June 2020

Cooperation and the Management of Local Common Resources in Remote Rural Communities

Evidence from Odisha, India

\author{
Patrick Ward \\ Muzna Fatima Alvi \\ Simrin Makhija \\ David Spielman
}

Environment and Production Technology Division 


\section{INTERNATIONAL FOOD POLICY RESEARCH INSTITUTE}

The International Food Policy Research Institute (IFPRI), a CGIAR Research Center established in 1975, provides research-based policy solutions to sustainably reduce poverty and end hunger and malnutrition. IFPRI's strategic research aims to foster a climate-resilient and sustainable food supply; promote healthy diets and nutrition for all; build inclusive and efficient markets, trade systems, and food industries; transform agricultural and rural economies; and strengthen institutions and governance. Gender is integrated in all the Institute's work. Partnerships, communications, capacity strengthening, and data and knowledge management are essential components to translate IFPRI's research from action to impact. The Institute's regional and country programs play a critical role in responding to demand for food policy research and in delivering holistic support for country-led development. IFPRI collaborates with partners around the world.

\section{AUTHORS}

Patrick Ward (patrick.s.ward@dukekunshan.edu.cn) is an assistant professor of environmental economics and policy in the iMEP program at Duke Kunshan University. He was formerly a Research Fellow in the Environment and Production Technology Division at the International Food Policy Research Institute (IFPRI), Washington, DC.

Muzna Fatima Alvi (m.alvi@cgiar.org) is an Associate Research Fellow in IFPRI's Environment and Production Technology Division, New Delhi.

Simrin Makhija (s.makhija@cgiar.org) is a Research Analyst in IFPRI’s Environment and Production Technology Division, Washington, DC.

David Spielman (d.spielman@cgiar.org) is a Senior Research Fellow in IFPRI’s Environment and Production Technology Division, Washington, DC.

\footnotetext{
Notices

${ }^{1}$ IFPRI Discussion Papers contain preliminary material and research results and are circulated in order to stimulate discussion and critical comment. They have not been subject to a formal external review via IFPRI's Publications Review Committee. Any opinions stated herein are those of the author(s) and are not necessarily representative of or endorsed by IFPRI.

${ }^{2}$ The boundaries and names shown and the designations used on the map(s) herein do not imply official endorsement or acceptance by the Intemational Food Policy Research Institute (IFPRI) or its partners and contributors.

${ }^{3}$ Copyright remains with the authors. The authors are free to proceed, without further IFPRI permission, to publish this paper, or any revised version of it, in outlets such as joumals, books, and other publications.
} 


\title{
Cooperation and the management of local common resources in remote rural communities: Evidence from Odisha, India *
}

\author{
Patrick S. Ward ${ }^{1,2}$, Muzna Alvi ${ }^{3}$, Simrin Makhija ${ }^{2}$, and David J. Spielman ${ }^{2}$ \\ ${ }^{1}$ Duke Kunshan University, China \\ ${ }^{2}$ International Food Policy Research Institute, USA \\ ${ }^{3}$ International Food Policy Research Institute, India
}

\begin{abstract}
It is widely recognized that local management of common pool resources can be more efficient and more effective than private markets or top-down government management, especially in remote rural communities in which the institutions necessary for the enforcement of centrally-imposed regulations may be weak or prone to elite capture. In this paper, we explore the propensity for cooperation in the management of local common resources by introducing a variant of a public goods game among remote rural communities in the state of Odisha, in eastern India. We explore various patterns of cooperation, including free riding behavior, unconditional cooperation (altruism), and conditional cooperation, in which individuals' propensity toward cooperation is tied to their beliefs about the level of cooperation among their peers. We find that a significant portion of our sample fall into this latter category, but also that their expectations about the level of contributions among their peers is somewhat malleable, and beneficial activities from external actors such as NGOs can foster increased social cohesion which increases both the level of these expectations and the manner in which these expectations are translated into subsequent cooperative behavior. We also find that cooperation is somewhat fragile, with group heterogeneity and risk in the returns to cooperative behavior posing a threat to the stability of the cooperative system.
\end{abstract}

Keywords: Local public goods, local common resources, experimental games, voluntary contribution mechanism, India

*Corresponding author: patrick.s.ward@dukekunshan.edu.cn. This work was supported by funding from the CGIAR Collaborative Research Program on Agriculture for Nutrition and Health (A4NH) and the Bill and Melinda Gates Foundation through the Technical Assistance and Research for Indian Nutrition and Agriculture (TARINA) project. We have benefitted from helpful comments provided by participants at the 2019 Agricultural and Applied Economics Annual Meeting and the 2019 China Agricultural Economics Review-International Food Policy Research Institute Annual International Conference. The authors declare that they have no known competing financial interests or personal relationships that could have appeared to influence the work reported in this paper. All remaining errors are our own. 


\section{Introduction}

The theory of public goods has long established a role for the centralized provision of goods and services for which private markets do not exist due to the disparities between the marginal private benefits that accrue to each member of society and the total benefits that accrue to society writ large. The solution to such market failures is typically for the government to intervene and provide these goods and services to all members of society without excluding access or permitting one member's enjoyment of these goods or services to diminish the enjoyment of other members. In remote rural communities in many developing countries, however, centralized institutions often fail to provide public goods and public governance that could enhance overall social welfare. ${ }^{1}$ This is perhaps especially true when it comes to the management of many locally-managed common pool resources, for which property rights are typically not clearly defined. The management of these community resources thus typically requires collective action, often facilitated through decentralized and often endogenously-formed institutions that promote cooperation through communication and social sanctioning.

In this study, we explore rural community members' propensity for cooperation using a series of experimental games conducted in the Kandhamal and Kalahandi districts in the state of Odisha, India. These two districts are very remote, with a relatively high concentration of members of scheduled tribes (ST) and scheduled castes (SC). The experimental games we employ are a variant of public goods game, specifically the voluntary contribution mechanism (VCM). In a general VCM, individuals are provided with an initial endowment, and they must choose how much of this endowment to use for private consumption and how much to contribute to a public good. Individuals derive utility from both private consumption as well as consumption of the public good, but the amount of the community good that is produced and shared among all members of the community is a function of the voluntary contributions of the community members. The returns to private consumption and the per capita marginal returns to public contributions are specified

\footnotetext{
${ }^{1}$ This phenomenon is not exclusive to developing countries, nor to rural communities. Indeed, many nongovernmental and/or philanthropic organizations play this role, arguably due to government failure rather than market failure.
} 
such that (i) the game yields a unique (single period) Nash equilibrium in which no participant contributes to the public fund, but simultaneously that (ii) deviations from this equilibrium are potentially welfare enhancing, such that the Pareto optimal allocation of endowments for the group is for everyone to invest their entire endowments toward the production of the public good. We employ a simplified version of the traditional VCM that has recently been employed in several other developing countries (Cárdenas et al., 2017). Rather than participants facing a decision regarding the proportion of their endowment to contribute to the public good, participants make a binary decision about whether to contribute or to retain his or her endowment. While this precludes analysis regarding the level of investment in local public goods, it is perhaps more reflective of the true nature of cooperation in remote rural settings, specifically mimicking the "all-in" decision that must often be made regarding cooperation in the management of local public resources.

We introduced additional variants to the VCM to allow us to explore various dimensions of heterogeneity in participants' contribution decisions in the VCM. In particular, we explore how private and collective risk condition individual farmers' willingness to contribute to local public goods, under the assumption that payoff stochasticity can erode cooperation. In particular, our baseline experiment consisted of a standard VCM with a one-shot exchange in which the returns to private consumption and the per capita marginal returns to public contributions were fixed and known to all. We followed this baseline experiment with subsequent rounds introducing risk into the private and public returns, with the order of the private risk and collective risk rounds randomized to prevent order effects. We control for exposure to a large, international nongovernmental organization's (CARE-India) development interventions to assess the extent to which various programs can engender greater cooperation within these remote villages. ${ }^{2}$ We also consider the effects of group composition on individual behavior. To do so, we randomized the composition of groups at the village level along several dimensions. First, the size of the group was randomized, with groups

\footnotetext{
${ }^{2}$ CARE-India is an affiliate of the CARE International Confederation, which works in over 100 countries worldwide. CARE-India has been working in India for nearly 70 years, with a primary focus on poverty alleviation promoting social inclusion. According to their website, their overall goal is "the empowerment of women and girls from poor and marginalized communities, leading to improvement in their lives and livelihoods."
} 
in half of the villages consisting of small groups (six individuals) and the groups in the other half of villages consisting of large groups (12 individuals). ${ }^{3}$ Second, the sex composition of groups was randomized. In half of the villages in our sample, groups were single-sex groups (consisting of either only males or only females). In the other half of villages, the groups were mixed-sex, consisting of both males and females. Third, we varied the nature of the sex-mixing to see whether there was an effect of relational proximity. To do so, in half of the mixed-sex villages, the groups consisted of familial pairs of males and females (e.g., husbands and wives, though we did not restrict the familial pairs to be marital pairs). In the other half of villages with mixed-sex groups, the groups consisted of unrelated males and females.

Finally, we are interested in exploring patterns of cooperation. The literature on cooperation has tended to classify individuals in VCMs (and other such games that force participants to confront a social dilemma) as falling into one of three distinct categories: free riders, who are wholly self-interested and refuse to cooperate no matter how great the potential returns from cooperation; unconditional cooperators, who have an overriding sense of altruism and commitment to cooperation; and conditional cooperators, who are willing to pursue the social optimum - but only if they expect a number of their companions to do so as well. We examine individuals' expectations about other game members' contributions, and assess the extent to which this influenced cooperative behavior.

We study the impact of these dimensions of heterogeneity on cooperation. Our baseline level of cooperation was rather low, suggesting that the participants in our sample might perceive the selfinterested optimality of the strategy of private consumption over the social optimality of community good contributions. Consistent with recent research across a number of contexts, we find that risk does have an impact on individual behavior, but the nature of the risk is crucial; specifically, risk affecting the returns on the community good results in lower levels of cooperation compared with either the baseline or private risk scenarios. Unlike other studies, however, we find that risk affecting

\footnotetext{
${ }^{3}$ While it was our intention to have groups of six or 12 participants, the actual size of the groups depended on the number of individuals who showed up to participate the experimental games. Of those groups that were supposed to consist of six participants, the average actual group size was 5.5, while the average actual group size for those groups that were supposed to consist of 12 participants was 10.7.
} 
the returns to private consumption leads individuals to cooperate more by increasing contributions to the local community good relative to the baseline. These results are driven primarily by the sources of uncertainty. When there is risk in the returns to the public good, there are two sources of uncertainty that erode cooperation (uncertainty around the decisions others will make and uncertainty around the returns on the community good). When there is risk in the returns to the private good, there are competing uncertainties (uncertainty around the decisions others will make versus uncertainty around the returns on private consumption), but perceptions of social cohesion tend to encourage cooperation in such situations. Across all three rounds, perceptions of social cohesion are considerably higher than the actual levels of cooperation, but these expectations are positively correlated with individual behavior.

Contrary to much of the public goods literature, that suggests increasing community size increases free-riding behavior, and contrary to much of the existing literature on public goods games that argues against size effects (in the absence of concomitant reductions in the marginal per capita returns to the public good), we find evidence that larger groups had higher rates of cooperation than smaller groups. The sex composition of groups also emerged as an important determinant of behavior, with mixed-sex groups exhibiting lower levels of cooperation than single-sex groups. This effect was ameliorated to some degree if the mixing included familial pairs. We interpret this as evidence that cooperation is likely to be highest in more homogeneous groups, but relational proximity may offset the cooperation-eroding effects of group heterogeneity.

Interestingly, we find that those villages that had been the beneficiaries of programming by CARE-India had higher rates of cooperation, both during the baseline experiment (in which there is no risk) as well as under the collective risk experiment. Groups that had benefitted from CARE programming also exhibited higher degrees of social cohesion, both in terms of higher perceptions of social cohesion, as well as a stronger positive correlation between the expected proportion of contributions and individuals' behavior. 


\section{Background}

In many rural communities in developing countries, many individuals' livelihoods are inextricably dependent upon local common property resources such as grazing lands; inshore fishing grounds; irrigation facilities such as polders, canals, and tanks; subterranean aquifers; forests; and wildlife habitats (Seabright, 1993). Many of these local common property resources take the form of locally-managed natural resources and have properties that are reminiscent of both public goods and open-access resources. Unlike 'pure' public goods, the consumption of locally-managed natural resources is rivalrous: one person's consumption of a finite natural resource necessarily implies that there is less of the resource to be consumed by others in the society. Yet these resources are also not 'purely' non-excludable, since access to these resources can typically be governed by local institutions, even if these are as informal as 'norms' or 'rules of conduct.' But an important feature that often emerges in the context of such locally-managed resources is that access to the resource is fairly unrestricted within the community, but the rivalrous nature of consumption shares the principal feature of familiarly tragic commons (Hardin, 1968).

Around the world, the value of these resources and the myriad environmental and ecosystem services that they provide have long been recognized, and governments and institutions (such as private markets) have arisen to manage these resources and to provide for their beneficial use by future generations. In many developing countries, however, enforcement is often too weak, or communities that manage these resources are often too remote for state intervention to provide a meaningful means to oversee the management of these resources (Bardhan, 1993).

In the absence of a robust governance regime or institutions to provide these local public goods or to sustainably manage the use of these local commons, there is an opportunity for local governance and collective action. Indeed, there are many examples in developing countries of local communities successfully managing local common resources (Wade, 1987; Ostrom, 1990; Bardhan, 1993). Several researchers have attempted to understand the conditions under which these institutions can foster cooperation in the management of these local commons. Ostrom (1990, Ch. 3) in particular details a variety of long-enduring communities that have successfully managed common 
property resources, both in developed countries as well as developing countries. As a result of the numerous field studies that she and her co-authors conducted across these myriad sites, she summarized a series of eight design factors that most of the successful institutions had in common: (1) clearly defined boundaries (i.e., defining who is in the community, and who is out of the community); (2) congruence between the rules governing the provision and use of resources with local conditions; (3) collective choice arrangements allowing individuals affected by the collective's rules to participate in their modification; (4) the accountability of monitors - who audit the provision and uses of the resource - to the group, regardless of whether they are themselves members of the group (and therefore users of the resource themselves); (5) graduated sanctions with the seriousness or extent of violations of the collective's rules; (6) fast and fair conflict resolution; (7) local autonomy from external government authorities in the management of the resource; and (8) polycentric governance ensuring that the collectives maintain appropriate relations with other tiers of rule-making authority, such as external government authorities.

Although these conditions are frequently viewed by modern theorists as pre-conditions for the successful management of local commons, and indeed they have been realized even in many developing countries, they are far from ubiquitous. Prominent examples emerge from the Indian context. Beteille (1983), for example, documents cases in which access to the common property resources is restricted to relatively privileged members of Indian society, based on, for example, religion and caste. In other cases, the provision of local public goods and the management of local commons introduces a "social dilemma" in the organization of rural societies, in which individual incentives are at odds with social well-being (Cardenas and Carpenter, 2008). In the midst of such social dilemmas, there is a need for very grassroots-level cooperation. Yet cooperation is often difficult to enforce exogenously, since by its very definition, cooperation is voluntary. While Seabright (1993) has suggested that "cooperation can be habit-forming", depending on historical and traditional considerations, it has also been observed that cooperation can often be quite fragile, and can be influenced by a number of factors, including trust, social cohesion, and risk (Kocher et al., 2015).

When researchers have attempted to study these types of collective action problems, they have typically done so through the lens of prisoner's dilemma games, which economists frequently cast 
in terms of a public goods problems (Croson, 2008). Experimental economists have long studied the propensity to cooperate in various forms of public goods experiments, including the voluntary contribution mechanisms (VCM; e.g., Isaac et al., 1984), provision point mechanisms (PPM; e.g., Bagnoli and Lipman, 1989), and common pool resource (CPR) management mechanism (e.g., Walker et al., 1990). While these mechanisms differ in the nature of the decision that participants make in the game and the manner in which the public goods are generated and distributed to the participants (i.e., the production function), they share a common feature of externalities: each individual affects and is affected by the other participants. Additionally, each game presents participants with a social dilemma in which the dominant strategy results in a socially inefficient Nash Equilibrium, while an alternative strategy yields a social optimum (Cardenas and Carpenter, 2008). Deviations in observed behavior from the dominant strategy are frequently attributed to a propensity for cooperation, altruism, or various other-regarding motivations. The primary setting for most of these experiments has been the laboratory, typically with subjects drawn from a pool of university students. A few of these have been implemented in the field (as opposed to a laboratory setting), and some have even been implemented in developing countries (e.g., Barr, 2001; Carpenter et al., 2004; Karlan, 2005; Cardenas et al., 2000, 2002; Meinzen-Dick et al., 2018). Over the years, some stylized facts have emerged regarding participants' behavior in these games. In particular, it is commonly found that initial cooperation rates are in the range of 40-60 percent, with the level of cooperation steadily declining over successive rounds of the game, presumably as participants learn the dominant strategy. The level of cooperation is strongly correlated with the marginal per capita return (MPCR) on cooperation (a parameter of the public good production function that defines how the public good is generated and distributed to the participants), with cooperation declining as the MPCR declines, thus suggesting that cooperation is not the result of participants simply making mistakes (Brandts and Schram, 2001). Despite being a dominant strategy, a small minority of participants free ride as an initial strategy. Contrary to what is typically theorized in the public economics literature, the propensity for free-riding does not increase as group size increases, though when combined with a reduction in the marginal per capital returns to cooperation, free-riding does increase (Isaac and Walker, 1988). 
Given the frequency with which researchers observed cooperation in the various types of public goods games, there were attempts to broadly classify the observed behaviors. Offerman et al. (1996), for example, classified participants into five categories based on what they defined as 'value orientations.' According to their taxonomy, participants can be classified as competitors, who simply want to be better off than their neighbors; individualists, who try to maximize their own welfare; cooperators, who simultaneously pursue maximizing both their own welfare and the welfare of others in the group; altruists, who unconditionally seek the best for others regardless of the impacts on themselves; and aggressors, diametrically opposed to the altruists, who seek the worst for others, regardless of the impacts on themselves.

Others have proposed a simpler taxonomy, consisting of unconditional cooperators, acting purely out of altruistic motives; free riders, who follow purely self-interested strategies; and conditional cooperators, who are willing to cooperate if they expect the overall level of cooperation among their peers as exceeding some minimum threshold. Most studies would classify the bulk of their participants as conditional cooperators. Cárdenas et al. (2017) found conditional cooperation to be prevalent and that the nature of risk was an important factor in cooperation. Conditional cooperation implies that expectations about the actions of others can be an important determinant of cooperation in these environments. But these expectations are essentially a function of social cohesion, which is rarely exogenous. Many interventions by civil society support behavioral change, so it is not difficult to imagine how targeted interventions could increase voluntary cooperation and leverage conditional cooperation to generate a virtuous cycle of self-reinforcing feedbacks. If interventions increase the perceived value of cooperation, then this might lead to increased expectations of cooperation, which in turn could lead to increased levels of cooperation. In addition, the composition of the community may have an impact on the propensity to cooperate. Does the size of the group managing the resource matter for cooperation? For example, do larger projects increase the propensity for people to free-ride, thinking that they can 'fly under the radar'? Additionally, are people more prone to cooperate with people that are more similar to them? These are just a few of the questions that the present study aims to examine. 


\section{$3 \quad$ Theory and causal inference}

The causal theory that underlies the empirical methods below can best be depicted through graphical analysis, specifically a directed acyclic graph (DAG; Pearl, 2009). ${ }^{4}$ The DAG that represents the causal theory being explored in the present paper is depicted in Figure 1. In this diagram we theorize the causal relationship between exposure to pro-social interventions $T$ (e.g., through NGO programming) and both cooperative behavior $C$ and expectations about the actions of others $E$. But we also theorize that expectations $E$ have an effect on subsequent cooperative behavior. As such, exposure to the intervention $T$ has a two-pronged effect on cooperative behavior: the direct effect from $T$ to $C$, and the indirect effect through the mediator $E$. In addition to these causal relations, we posit there are other factors that may affect both expectations and cooperative behavior $x_{1}$, or only expectations $x_{2}$ or only cooperative behavior $x_{3}$. Factors that might affect either expectations and cooperative behavior or both might include individual characteristics such as age, gender, caste (in the case of India), the nature of risk exposure and one's personal risk preferences, etc. There is an additional relationship that is modeled in Figure 1, that denoted by node $S$ and its relationship to both $T$ and $C$. This node represents potential selection bias, which may arise if, for example, the NGO introducing their pro-social programming specifically targeted certain villages along dimensions that might also be related to the level of cooperative behavior in the village.

The primary relationship in which we are interested is the relationship between exposure to NGO programming and cooperative behavior. In addition to the direct causal path $T \rightarrow C$, there are several "backdoor paths" that must be dealt with to afford a causal interpretation. ${ }^{5}$ In particular, there are two backdoor paths that go through the mediator E: the "chain of mediation" $T \rightarrow E \rightarrow C$ and the more enigmatic $T \rightarrow E \leftarrow x_{1} \rightarrow C$. If this latter backdoor path were not present, then we could simply control for expecatations in estimating the relationship between $T$

\footnotetext{
${ }^{4}$ As Pearl (2009) and Pearl and McKenzie (2018) note, causal graphs such as DAGs have been around since Sewall Wright first used them in the 1920s, though they have only recently begun to make a resurgence in statistics and other sciences (see, for example, Morgan and Winship, 2010). These types of causal graphs are still relatively uncommon in economics, but this trend is rapidly changing (Cunningham, 2019).

${ }^{5}$ Pearl (2009) has demonstrated that, according to his Backdoor criterion, if all backdoor paths are closed (or blocked), then a causal effect between two variables can be identified.
} 
and $C$. Since $E$ is a "collider" (also referred to as an inverted fork of mutual dependence) in the path $T \rightarrow E \leftarrow x_{1} \rightarrow C$, controlling for $E$ alone opens up the additional backdoor path $T \rightarrow x_{1} \rightarrow C$. Thus, we further need to control for $x_{1}$ to close this newly opened backdoor. Importantly, we do not need to worry about $x_{2}$ nor $x_{3}$ : since these terms do not lie along any backdoor paths between $T$ and $C$, they should not affect our estimation of the causal effect in which we are most interested.

In addition to the two backdoor paths that go through the mediator $E$, there is another backdoor path that goes through the confounder $S$, representing potential selection bias: $T \leftarrow S \rightarrow C$. This confounding might arise if, for example, there are characteristics of villages that make them (or their individual villagers) more cooperative that simultaneously makes them more likely to be targeted for NGO programming. Our strategy for dealing with this potential backdoor path is multifaceted. First, as described in greater detail below, we apply a matching algorithm on preintervention (i.e., 2011) village census data that permits us to construct an approximate comparison group that should control for the effect of $S$ and close this backdoor path. Second, we can compare the characteristics of households in those villages that were recipients of the NGO's programming and those that were not, and to control for any characteristics for which there are differences that demonstrate a low probability of having arisen purely due to chance. ${ }^{6}$ Third, we note that, based on direct communication with the NGO responsible for implementing the activities, there is apparently no detailed criteria for village selection, such that the assignment of villages to the treatment (i.e., receiving programs from the NGO) could be viewed as quasi-random. We do not rely on this assumption of quasi-random treatment assignment, but by construction of our comparison group through matching on pre-intervention data and by controlling for observable individual characteristics and village fixed effects, we have considerable confidence that this backdoor path is closed and does not bias or impede our causal inference. As a final approach, we perform some sensitivity analysis to test for coefficient stability. In particular, we follow the approach proposed by Oster (2019) that recognizes that the observed changes in coefficients (e.g., when new controls are intro-

\footnotetext{
${ }^{6}$ This is akin to testing for imbalance and controlling for those observable characteristics for which there is imbalance. Where the strategy differs, obviously, is that we are not testing for balance prior to the some intervention, and are therefore not able to isolate whether exposure to the NGO's programs was responsible for some of the observed differences.
} 
duced) provides information about the possible impacts of omitted variables on these coefficients, and allows for a bias adjustment.

\section{Empirical methods}

\subsection{Voluntary contribution mechanism experimental protocol}

The experimental protocol we propose to use to study farmers' cooperation in the management of local common resources and the provision of local public goods is based on a variant of a traditional VCM recently used by Cárdenas et al. (2017), who used a framed experiment to understand how private and collective risk condition individual farmers' willingness to contribute to public irrigation infrastructure. The particular variation of the VCM that we employ allows for risk in both the returns to private consumption and the public goods production function. Risk is obviously an important part of livelihoods among rural residents in developing countries, and given the nature of uncertainty surrounding the returns to common property natural resources and their shared management, gaining additional insight into how individuals respond when facing different sources of risk is of great interest and policy relevance. Experimental evidence has demonstrated that payoff stochasticity can erode cooperation (Bereby-Meyer and Roth, 2006), but Cárdenas et al. (2017) have shown that - in some contexts - the nature of the risk (i.e., individual versus collective) matters.

Our experiment consisted of three rounds, each following the same basic structure. The baseline round was designed like a typical, one-shot VCM. In a typical VCM, individuals are given an initial endowment $\left(Z_{i}\right)$, and they must choose how much of this endowment to use for private consumption and how much to contribute to a community good $\left(m_{i}\right)$. Most authors have assumed that participants in the game derive utility from both private consumption as well as consumption of the community good, such that individual $i$ 's utility function be written as

$$
U_{i}=u_{i}\left[Z_{i}-m_{i}+\left(\frac{1}{N}\right) G\left(m_{i}+\sum_{j \neq i} m_{j}\right)\right]
$$


where $Z_{i}-m_{i}$ represents the amount of private consumption, $\left(\frac{1}{N}\right) G(\cdot)$ is the per capita return from the community good. The production function $G\left(\sum_{i} m_{i}\right)$ here is linear, since the more that is allocated to the public good, the greater the social benefits. This linearity has two important implications (Croson, 2008). First, subject to appropriate parameterization, this game yields a unique (single period) Nash equilibrium in which no participant contributes to the community good. $^{7}$ Second, however, and again subject to appropriate parameterization, is that deviations from this equilibrium are potentially welfare enhancing, such that the Pareto optimal allocation of endowments for the group is for everyone to invest their entire endowments toward the production of the public good. ${ }^{8}$

If the utility function in equation (1) were indeed the correct specification of the utility function and individuals were only concerned with utility of own consumption, then given the manner in which most of these games are specified, with $u_{i}\left(Z_{i}\right)>\left(\frac{1}{N}\right) G\left(m_{i}+\sum_{j \neq i} m_{j}\right)$, then the Nash equilibrium should result. Rather, we allow for an altruism function $\Psi: \mathbb{R}_{+} \rightarrow \mathbb{R}_{+}$to contribute to individual utility, mapping others' enjoyment of the benefits of the public good to contribute to individual utility:

$$
U_{i}=u_{i}\left\{Z_{i}-m_{i}+\left(\frac{1}{N}\right) G\left(m_{i}+\sum_{j \neq i} m_{j}\right)+\Psi\left[\left(\frac{N-1}{N}\right) G\left(m_{i}+\sum_{j \neq i} m_{j}\right)\right]\right\}
$$

It is perhaps useful to think of $\Psi[\cdot]$ as reflecting individual $i$ 's indirect enjoyment of the public good, or $i$ 's enjoyment of others' enjoyment of the public good. In designing our experiment, we opted to simplify the participants' decisionmaking and reduced the consumption/contribution decision to a binary one: either they choose to privately consume their endowment, or they choose to contribute to the community good. While the binary nature of our contributions precludes a richer analysis of proportional contributions, the voluntary binary contribution decision is certainly

\footnotetext{
${ }^{7}$ For this to hold, the experiment must be parameterized in such a way that the MPCR to the community good, $1 / N G^{\prime}(\cdot)$, should be less than the return from the private good. This ensures that no individual has a selfish incentive to contribute to the production of the public good.

${ }^{8}$ For this to hold, the experiment must be parameterized in such a way that the social benefit from all members contributing their endowments to the creation of the community good is greater than the foregone private benefit. This ensures that contributing to the creation of the community good is socially optimal.
} 
easier for relatively uneducated populations to understand, and is arguably a closer approximation to the cooperation decisions that the respondents face on a regular basis.

Obviously, at the time the decision is made, the participant does not know the number of coparticipants who would be contributing to the community good, so equation (2) reflects the realized benefits of a particular outcome, rather than providing a tractable basis for deriving a decision rule. Rather, given the uncertainty in co-participants' cooperation, we assume the participant chooses $m_{i}=0$ or $m_{i}=1$ to maximize the expected utility that would be derived from either consuming her endowment or contributing her endowment to the community good. In the baseline round, each participant was given an endowment of one token, and had to decide between private consumption with a return of INR 20, or contributing to a group fund that provided a community good that would generate a MPCR of INR 10 for each token invested by group members. Notice that the Nash equilibrium condition (i.e., where each player's single period dominant strategy is to contribute nothing to the group fund) still holds (INR $10<$ INR 20), but contributions to the group fund are socially efficient (i.e., Pareto optimal) for group sizes greater than 2. In our experiment, villages were randomly allocated to consist of "small groups" (of 6 participants each) or "large groups" (of 12 participants), so in all cases participants faced the social dilemma of rational self-interest versus social optimization.

In the private risk round, the baseline protocol was modified such that private returns (i.e., the returns to consumption of the endowment rather than cooperation) were stochastic. Under these conditions, there is uncertainty in the returns to both private consumption and contributions to the community good, with the latter due to uncertainty around the decisions of other members of the group (though the MPCR is constant). Operationally, the game worked very similar to the one described above, but after the participants allocated their tokens to either private consumption or the group fund, we tossed a fair coin with 50/50 odds of a double-or-nothing return on private consumption. If the coin turned up heads, the private return would be INR 40, whereas if the coin turned up tails, the private return would be INR 0. Regardless of the decision to keep or contribute one's individual token, each individual would still receive the MPCR of INR 10 per token contributed to the group fund. 
In the collective risk round, the baseline protocol was modified such that the MPCR on contributions to the community good were stochastic, while the returns to private consumption were fixed. Under these conditions, there are two sources of uncertainty in contributing to the community good: those associated with the MPCR on contributions to the community good as well as the overall level of cooperation in the game. If an individual retained their token, they would still earn a private return of INR 20. But after the individual decisions were made, we tossed a fair coin, again with 50/50 odds of a double-or-nothing MPCR on contributions to the group fund. If the coin turned up heads, the MPCR on group fund contributions would be INR 20, whereas if the coin turned up tails, the MPCR on group fund contributions would be INR 0 .

Each of the three rounds was treated as a one-shot game in which individuals made a binary decision about whether to voluntarily contribute to the public fund. To avoid learning effects, we did not provide any feedback to participants regarding the outcomes of their decisions until after all experiments were performed. Croson (2008) notes that, in a finitely repeated game, backward induction supports the Nash equilibrium of no group fund contributions, so it is thought that, over the course of several rounds, individuals will effectively learn this dominant strategy. Indeed, many studies reporting on VCM experiments observe contributions to the community good at roughly half of an individual's endowment during the first round, with contributions steadily declining over subsequent rounds as a proportion of the individual's endowment as individuals learn the dominant strategy.

Following Cárdenas et al. (2017), we controlled for order effects by randomizing the order of the private risk and collective risk rounds. Roughly half of the sample participants faced the private risk variant of the game following the baseline round, followed by the collective risk variant, while the other half proceeded with the collective risk and then the private risk game following the baseline.

In addition to randomizing the group size and the order of the two rounds introducing stochasticity in returns to either private consumption of in the marginal per capita return on contributions to the public good, there were several other elements that were randomized over the course of the study. Specifically, the sex composition of the groups was randomized. In half of the villages in our sample, groups were single-sex groups (either men-only or women-only). So, for example, in a 
village that was randomly selected to consist of small groups (each consisting of six participants), there would be two groups each with six men and two groups each with six women. In a village that was randomly selected to consist of large groups (each consisting of 12 participants), there would only be one group of 12 men and one group with 12 women. In the other half of the villages, groups were mixed-sex groups, consisting of $1 / 2$ men and $1 / 2$ women. In this latter half of villages, we also varied the nature of the mixing. In half of the mixed-sex villages, the groups consisted of

mixed-sex familial pairs, while in the other half of the mixed-sex villages, the groups consisted of unrelated men and women.

The games were designed to be incentive compatible so that participants had economic incentives to reveal their true preferences in the course of the experiment. Following the completion of all three rounds of the game, one round was selected at random to be the basis for actual cash payments to participants, based upon their decisions and the decisions of others in the group for that round. If either the private risk round or the public risk round was selected as the basis for payment, a member of the enumeration team would flip a fair coin to determine the rate of return on private consumption or the MPCR on contributions to the community fund.

\subsection{Determinants of cooperative behavior}

Based on observed behavior from the baseline round and the subsequent modifications in the subsequent two rounds, it becomes clear that the contribution decision is a function of the idiosyncratic utility function $u_{i}$, which reflect individual and/or community characteristics $\mathbf{x}_{i}\left(u_{i} \equiv u_{i}\left(\mathbf{x}_{i}\right)\right)$, the MPCR to contributions to the community good (the production function $G$ ), the expected contributions of co-participants, and each individual's unobservable altruism function $\Psi$. We can write the participants' decision function as

$$
m_{i}=f\left(u_{i}^{*}\left(x_{1}, \ldots, x_{k}\right), G, E\left[\sum_{j \neq i} m_{j}\right], x_{i, u} ; \beta\right)+\varepsilon_{i}
$$


where $u^{*}(\cdot)=u(\cdot)$ when the arguments are deterministic and $u^{*}(\cdot)=E u(\cdot)$ when the arguments are stochastic, $x_{u}$ is some unobservable individual or community characteristics conditioning the contribution decision, $\beta$ is a vector of coefficients to be estimated, and $\varepsilon$ is an idiosyncratic error term capturing random variations in preferences, errors in optimization, etc. Operationally, we control for $u^{*}$ by including two dummy variables to reflect the existence of risk in returns to private consumption and risk in returns to the marginal returns on community good contributions, respectively. The vector of individual and community characteristics included in $\mathbf{x}$ should reflect attitudes toward risk, since there is at least some uncertainty in all scenarios. ${ }^{9}$ Initially, let us assume that $x_{u}$ is uncorrelated with any of other arguments in $m$. Then, given the binary nature of the contribution decision, this equation could simply be estimated as a linear probability model using least squares.

\section{Data}

The data used in this study come from both a primary survey and a series of experimental games (voluntary contribution mechanisms) conducted between February to March 2018 in Kandhamal and Kalahandi districts in the Eastern Indian state of Odisha (Figure 2). Both districts are quite remote and heavily rural, with only 7.8 percent of the population of Kalahandi living in urbanized areas, and less than 10 percent of the population of Kandhamal living in urban areas according to the 2011 Census of India (the most recent census). Accordingly, both districts are also sparsely populated. Much of Kandhamal is forested, and according to the 2011 census, the population density was only 91 persons per square kilometer. Much of Kalahandi is also covered with a dense forest, though it is less sparsely populated than Kandhamal, with just under 200 persons per square kilometer according to the 2011 census. Additionally, both districts consist of a large

\footnotetext{
${ }^{9}$ In the empirical work that follows, we classify individuals as being very risk averse, moderately risk averse, risk neutral, moderately risk loving, and very risk loving. These classification are based on responses to a survey question in which they select a statement that most closely corresponds to their attitudes toward taking risks, ranging from "I prefer not to take risks at any time, regardless of the potential benefits" (very risk averse) to "I always prefer taking risks over playing it safe, regardless of the potential losses" (very risk loving).
} 
proportion of members of scheduled tribes (ST) and scheduled castes (SC). ${ }^{10}$ Consequently, public institutions remain relatively weak, and Kandhamal in particular has been a hotbed for NaxaliteMaoist insurgencies.

Since one of our primary interests is understanding the extent to which social interventions can encourage greater cooperation, we exploit heterogeneity in the provision of community-based services by a large, international NGO (CARE-India) that has been operating in the sample area. CARE-India had been operating under two projects in this area, one project aimed at increasing women's empowerment and agency (Pathways to Empowerment, or Pathways, for short), and the other aimed at improving the nutrition-sensitivity of food systems (Technical Assistance and Research for Indian Nutrition and Agriculture, or TARINA). Both projects leveraged the extensive network of pre-existing women's self-help groups that operate throughout Odisha. Although one of Pathways' goals was to increase solidarity among SC and ST women farmers, it also strove to encourage more sustainable agricultural practices to increase agricultural productivity and diversify livelihood strategies. TARINA, on the other hand, had much more of a focus on nutritious food production systems. TARINA sought to encourage the introduction of legumes into the predominant rice monocrop system; introduce nutrition education and awareness-building (specifically around consumption diversification and the cultivation of kitchen gardens); improve goat husbandry, feed management, and value chain linkages; and improve storage technologies to reduce postharvest losses.

Our research activities were introduced after the CARE-India had been active in the sample area for several years, so our strategy for identifying a plausible counterfactual relied upon the retrospective construction of a comparison group based on propensity score matching using preintervention census data. First, we used data from the 2011 census of India to identify all villages

\footnotetext{
${ }^{10}$ The "scheduled caste" and "scheduled tribe" labels are official designations conferred on historically disadvantaged social groups in India, including those members of lower castes formerly referred to as "untouchables." These official designations were the result of the The Constitution (Scheduled Castes) Order of 1950 and the Constitution (Scheduled Tribes) Order of 1950, respectively. These designations confer some advantages on its members, such as reservations or quotas meant to ensure political representation and equal opportunities for education and the administrative services. Despite such reservations, however, members of SC and ST communities still suffer economic and social disadvantages.
} 
from the same blocks (sub-district administrative units) within which CARE-India implemented activities under two of the two projects. From this list, villages were divided into two groups: those where CARE-India had subsequently implemented Pathways and/or TARINA activities (these were classified as treatment villages), and those where CARE-India had no active or past programs as of the time of our study (these were classified as comparison villages). We then estimated propensity scores (predicted probability of treatment by CARE's interventions) for each village using a probit model and a comprehensive list of relevant variables. Using these propensity scores, we used nearest neighbor matching to pair each treatment village with a control village which had the closest propensity score. This gave us 119 pairs of treatment and control villages. From these, 42 pairs of villages were randomly selected to get an equal number of treatment and control villages, for a total sample of 84 villages.

Within each selected village, the survey team identified all households actively engaged in agricultural cultivation with the assistance of the sarpanch (a type of local leader or administrator), and from this list 12 households were randomly selected for participation in our study. One adult man and one adult woman were interviewed from each household for a total sample of 1,960 respondents (980 men and 980 women). Each interview contained questions on household agricultural practices, consumption, assets, household composition, decision making, aspirations, and empowerment, as well as laboratory-in-field experiments to elicit preferences with respect to risk, loss, ambiguity, and time. Some questions were answered only by the primary decisionmaker, while others were answered by both the respondents. Later that day or the following day, all the respondents participated in a group game with other respondents in the village. ${ }^{11}$

Descriptive statistics for our sample are reported in Table 1. By design, our sample consists of half men and half women. On average, the participants in our study are about 42 years old, though participants from TARINA villages are slightly older (roughly 44 years old). The vast majority

\footnotetext{
${ }^{11}$ It is important to recognize that the village-level pairwise matching procedure described here can only account for observable differences between villages, leaving open the possibility of non-observable heterogeneity. As a result, treated (TARINA and Pathways) and comparison villages and households may differ on the basis of omitted observable variables or unobservable characteristics, and other factors. The matching strategies employed here were seemingly the best method available for constructing an adequate comparison group given the timeline for evaluation and the secondary data available.
} 
(95 percent) of participants are Hindu, though a slightly smaller proportion of participants from TARINA villages (90 percent) are compared to those from Pathways or comparison villages (96 and 97 percent, respectively). The remaining 10 percent of participants from the TARINA villages are Christian, as are the remaining non-Hindu participants from the Pathways and comparison villages. Roughly half of the participants are literate (in the sense that they can both read and write), with a slightly higher proportion in Pathways villages than in comparison villages. Pathways villages have a higher proportion of scheduled caste (SC) individuals than either TARINA or comparison villages, while TARINA villages have a higher proportion of scheduled tribe (ST) individuals than comparison villages.

\section{Results}

\subsection{Descriptive analysis of voluntary contributions}

Our analysis of the results from our voluntary contribution mechanism begins with simple descriptive and graphical analysis, before moving on to more rigorous statistical analysis. To begin, we first observe patterns of cooperation - defined as voluntary contributions to the community good - which are illustrated in Figure 3, broken out by round (baseline, private risk, collective risk) and by receipt of CARE's treatment (TARINA and Pathways versus comparison villages). Based simply on rates of cooperation, we observe 43 percent of participants contributing to the public fund during the baseline (no-risk) round of the public goods game. This is generally lower than the rates of cooperation observed across four countries in Cárdenas et al. (2017), though in that study the authors found rates of cooperation varied quite a bit from country to country. Our results suggest that the nature of risk can have an important effect on voluntary contributions. In the private risk round of the game, contributions increased to a mean of 48 percent, while in the collective risk round, the contribution rate dips to 41 percent. Examining the proportion of participants contributing across treatment and comparison groups, we find villages that have been engaged in activities under the TARINA program having higher rates of cooperation than either comparison 
villages or villages that have been engaged in the Pathways project. ${ }^{12}$ In the baseline and collective risk rounds, Pathways villages have a higher proportion of contributions than comparison villages ( $p$-values of 0.01 and 0.12 , respectively). There is essentially no difference in the proportion of contributions between Pathways and comparison villages in the private risk round ( $p$-value of 0.64$)$. At first glance, therefore, it would seem that there is fairly convincing evidence that CARE's activities under these two projects have been rather successful in encouraging cooperation and perhaps even a sense of altruism in the management of community resources.

\subsection{Classification of cooperative behavior}

From the experimental data, a significant portion of the participants appear to be acting as conditional cooperators, rather than unconditionally cooperating or free riding. Indeed, out of the 1767 participants in the experimental games for whom we have a complete set of observations, only 16 percent could be considered unconditional cooperators, acting purely out of altruistic motives, while 26 percent could be considered as free riders. The resulting 58 percent could be considered conditional cooperators. Much of this observed behavior seems tied to individuals' expectations about the level of cooperation among their peers, which is perhaps an indicator of social cohesion. Unconditional cooperators have considerably higher expectations about their peers' behavior than do conditional cooperators or free riders. Among unconditional cooperators, the average expected level of co-participants' cooperation in the provision of the community good is about 74, compared with 64 percent among conditional cooperators, and only 58 among those who opt to free ride. Clearly, as people expect that a greater number of their peers will cooperate, they themselves are more inclined to cooperate, such that increasing the level of expected cooperation among peers is an important step in pushing people toward unconditional cooperation.

Is there any evidence that these patterns may be influenced by exposure to CARE-India programs? While the illustrative evidence supporting this hypothesis is only relational rather than

\footnotetext{
${ }^{12}$ Based on $\chi^{2}$ tests in differences in proportions (using Yates' continuity correction), the difference in proportions of contributions between TARINA and Pathways villages in the collective risk round has a $p$ value of 0.09 ; all other differences between proportions of contributions between TARINA villages and either Pathways villages or comparison villages have $p$-values less than 0.03 .
} 
causal, it is nevertheless rather compelling. In particular, households in villages that have been recipients of CARE's programming appear much more likely to be unconditionally or conditionally cooperative, and less likely to be free riders. This is especially true among households in TARINA program villages. Among these households, 23 percent can be classified as unconditional cooperators, compared with 17 percent in Pathways villages and 14 percent in comparison villages. Additionally, 57 percent of TARINA households can be classified as conditional cooperators, suggesting that roughly 79 percent of households in TARINA villages are relatively inclined towards cooperation. Only 21 percent can be classified as free riders, compared with 27 percent in comparison villages and 25 percent in Pathways villages.

\subsection{Determinants of cooperation in voluntary contribution game}

Our statistical analysis assessing the extent to which CARE's programming, the nature of risk, and group composition influences individuals' willingness-to-cooperate through voluntary contributions takes the form of linear probability models, with standard errors adjusted for the clustering of contribution decisions at the individual level. To begin, we first examine the direct effects of TARINA and Pathways interventions on cooperation without controlling for the mediating effects of members' expectations of peer behavior. This allows us to confirm that participation in TARINA and Pathways programming is a predictor of voluntary cooperation. While this regression does not control for the mediating effect of expectations, it does, however, control for potential confounding through the various mechanisms described above. Coefficient estimates from this base regression are reported in Table 2, column (1). From this regression, we find that households in TARINA villages are 6 percentage points more likely to contribute than comparison households, while households in Pathways villages are no more likely or slightly less likely to contribute than households in comparison villages (the point estimate for the marginal effect is -0.01 , but the $p$-value is only 0.45 ). In column (2), we allow for the mediating effect of expecations. When we account for this mediator, the magnitudes of both the TARINA and Pathways effects are mildly attenuated, consistent with what would be expected if, indeed, expectations mediate the effect of these interventions on coop- 
erative behavior. In this case, the direct effect of TARINA on encouraging cooperative behavior is 0.05 (i.e., households from TARINA villages are 5 percentage points more likely to contribute to the community good), while, again, households from Pathways villages are no more likely or slightly less likely to contribute than households in comparison villages (the direct marginal effect is -0.006 , with $p$-value of 0.72 )

In column (3) we look at the effect of risk in the returns to either individual consumption of the endowment or in contributions to the community good. Not surprising, when there is private risk, individuals are 4 percentage points more likely to contribute to the community good, perhaps viewing it as a safer vehicle than the more uncertain returns on consuming the endowment. When there is collective risk, on the other hand, individuals are 2 percentage points less likely to contribute to the community good $(p$-value $=0.09)$. These results are consistent with previous research (e.g., Cárdenas et al., 2017) that cooperation may be quite fragile, depending on the relative risk of cooperation compared with more self-interested behavior.

In columns (4)-(5), we consider the effects of group composition, first by examining how group size affects contributions (column [4]), and then examining how the sex composition of the group affects contributions, both for mixed-sex groups in which the groups consist of sets of family members and for mixed-sex groups in which there are unrelated men and women (column (5)). While some studies have demonstrated that group size alone does not seem to be an important determinant of contributions to the community good, we actually find that group size does have a positive effect on contributions. Each additional member in the group increases the likelihood of voluntary contributions by 1 percentage points. While we certainly would not expect this to be a simple linear relationship, it is noteworthy that increasing the group size from six to 12 individuals led to a roughly 6 percentage point higher contribution rate. In this case, there is not an increased tendency for free-riding, even without the potential for punishment or sanctioning for doing so. Rather, it seems as though the participants understand the social dilemma of self-interest versus social optimality, and opt to at least pursue the latter, even at the expense of the former. It should also be noted that, because the ratio of the MPCR to the return on private consumption (in the baseline round) was $1 / 2$, there is a clear social dilemma for group sizes greater than two. For groups 
of six, full cooperation would result in each individual earning INR 60, whereas if everyone pursued their own self interest, they would each only earn INR 20.

In examining the effect of sex composition, we see that individuals in mixed-sex groups are less likely to contribute than members in groups consisting of members of the same sex. But the effects are partially ameliorated if the mixed-sex pairs are members of the same household. Individuals in mixed-sex groups consisting of individuals that they are wholly unrelated to are 4 percentage points less likely to contribute to the community good, while individuals in mixed-sex groups with a family member are only about 1 percentage points less likely to contribute. ${ }^{13}$ In a country like India, where there are still incredibly salient concerns over gender inequality, there is likely a significant amount of distrust among women toward their male peers. Yet this also likely says something about the effects of group heterogeneity more generally. More homogeneous groups likely have greater social cohesion, and this may facilitate greater degrees of cooperation.

One factor that explains a great deal of contributions to the community good across the board is the individual's expectations about the proportion of co-participants who are contributing to the community good. Across the different specifications, the marginal effect is between a 36 and 38 percentage point increase in the likelihood of contributions. And these expectations clearly drive much of the observed behavior. If individuals expected that none of their peers would voluntarily cooperate, their likelihood of voluntary cooperation is only about 20 percent. But this also does not mean that it is necessarily easy to tip the scales toward a more-likely-than-not level of voluntary cooperation. On average, in order to achieve a probability of voluntary cooperation in excess of 50 percent, individuals would need to expect that more than 81 percent of their peers would be cooperating.

\subsection{Mediation analysis}

We have previously maintained the assumption that individuals' expectations about their peers' contributions to the community good were influenced by the individual's exposure to CARE's

\footnotetext{
${ }^{13}$ This total effect consists of the linear combination of the effects for 'mixed-sex' and 'mixed-sex, same household.'
} 
programming (recall Figure 1). Previous research has pointed to beliefs or expectations as being important determinants of cooperation and contributions to collective action (e.g., Offerman et al., 1996; Fischbacher et al., 2001; Kocher et al., 2015), so if it is possible to influence these expectations through pro-social programs, that could have an important impact on the management of community resources. Is there any evidence that this is a valid assumption? As previously noted, in column (2) of Table 2, when we control for expectations, the marginal effect of participation in TARINA (and to a less extent, participation in Pathways) is mildly attenuated, which is what would be expected if indeed expectations were mediating the effect of exposure to CARE-India programming. Figure 5 illustrates the average level of expectations about co-partcipants' contributions to the community good, broken out by round and treatment status. The average expected level of co-participants' contributions is higher in TARINA villages than either Pathways or comparison villages across all three scenarios, though the $p$-values associated with the differences is less than 0.05 only in the baseline scenario (when comparing to both Pathways and comparison villages, with $p$-values of 0.05 and 0.03 , respectively). For TARINA villages, the expected proportion of co-participants' contributions to the community good is quite stable across all three scenarios, at roughly 0.68 percent. For both Pathways and comparison group villages, the expected contributions increase from the baseline round to the risky rounds, but are relatively stable across the risky rounds.

In Figure 4, we plot the village-level averages of individuals' contributions to the collective good (vertical axis) against the village-level average of individuals' expectations about the proportion of other participants' contributions to the collective good (horizontal axis), broken out by treatment group. As would be expected, and consistent with previous literature, there is evidence of a positive relationship between expectations and contributions: if individuals expect that a greater proportion of their co-participants will contribute to the public good, then they themselves are more likely to contribute. This positive relationship between expectations and contributions holds among all three groups, but is more pronounced in villages that have benefited from TARINA programming, as indicated by the steeper regression line for this bivariate relationship between expectations and contributions. 
Traditional mediation analysis (e.g., Baron and Kenny, 1986) requires that three conditions hold. First, the treatment variable must have an effect on the outcome variable with a $p$-value no greater than, for example, 0.10. This demonstrates that there is a causal relationship between the treatment and the outcome, though it does not parse out whether this effect is direct or whether it is indirect, passing through the mediator. Second, the treatment variable must have an effect on the mediator, also with a $p$-value no greater than 0.10 . This demonstrates that the treatment is a valid predictor of the presumed mediator, which is a necessary condition for mediation. Third, once the mediator is controlled for, the effect of the mediator on the outcome is nonzero, while the effect of the treatment on the outcome is reduced relative to when the mediator is not controlled for, reflecting the situation that at least a part of the effect of the treatment on the outcome passes through the mediator. The first and third of these conditions have already been demonstrated (at least in the case of TARINA) in Table 2 columns (1) and (2). ${ }^{14}$ Validating the second condition requires simply regressing expectations on treatment (TARINA and Pathways), based on a simple linear equation of the form

$$
\left(\frac{1}{n_{g}}\right) E_{i g}\left[\sum_{j \in g, j \neq i} m_{j}\right]=\alpha+T_{i g}^{\prime} \delta+\sum_{k=1}^{K} \gamma_{k} x_{i g k}+u_{i g}
$$

where the dependent variable $\left(\frac{1}{n_{v}}\right) E_{i g v}\left[\sum_{j \neq i} m_{j}\right]$ is individual $i$ 's expectation about the proportion of contributions to the experimental game by the other members $j$ of his or her group $g$, of size $n_{g}$. This is a function of the individual's exposure to the treatment (a vector of binary variables corresponding to exposure to TARINA and/or Pathways), as well as a series of individual and game characteristics, including the nature of risk in the different rounds of the game, as well as differences in group composition.

The results of these regressions are reported in Table 3. In column (1), we focus primarily on the relationship between exposure to TARINA and Pathways programming on expectations

\footnotetext{
${ }^{14}$ Although the effects of Pathways on voluntary contributions are attenuated when we control for the mediating effect of expectations of peers' contributions, the $p$-values for these estimated effects are well above 0.10 .
} 
of peers' behavior, which is symptomatic of enhanced social cohesion. As the results in column (1) indicate, individuals from villages that have been beneficiaries of TARINA programming have higher expectations about their peers' voluntary cooperation than do individuals from comparison villages (by about 4 percentage points), while individuals from Pathways have lower expectations about peers' voluntary cooperation (by about 2 percentage points).

By and large, these effects on peers' expectations do not change when we control for the nature of risk in the decision process (column [2]), and in fact these results suggest that risks in either private activities or in the returns to investments in the community fund both lead to higher expectations of peers' cooperation, each by about 2 percentage points. We do find evidence that there is heterogeneity in the effect of risk on expectations about peers' actions. In column (3) we interact the nature of risk with a binary variable indicating whether an individuals' village has participated in either TARINA or Pathways. For individuals from TARINA villages, risk in the returns to either private activity or to contributions in the community fund slightly diminishes expectations about peers' contributions, but their expectations are still about 3.3 percentage points higher than in the comparison group. A different story emerges for individuals from Pathways villages. Among these individuals, risk in the returns to private activity has no effect on expectations of peers' contributions, while risk in the returns to contributions to the community good further deteriorates their expectations, lowering expectations by 0.2 percentage points compared to a no-risk environment, and resulting in expectations that are 2.3 percentage points below that of individuals from comparison villages.

In sum, the evidence presented in Tables 2 and 3 are both confirmatory and contradictory of the causal model presented in Figure 1. The results do not support the overarching hypothesis that NGO programs writ large can generate both direct and indirect effects on pro-social behavior. A prime example of how this hypothesis fails is the evidence that is emerging regarding Pathways. In Table 2, participation in Pathways has a negative effect on voluntary contributions to the community good, though this direct effect is not measured precisely ( $p$-value of 0.72). Further, participation in Pathways seems to have diminished social cohesion, as the effect on participants' expectations of peers' cooperative behavior is also negative. 
These results do suggest, however, that the validity of our hypothesized causal relationship might depend on the NGO program 'treatment' being considered. The results clearly confirm our hypothesis that CARE-India's TARINA program has had a beneficial impact on individual's pro-social, cooperative behavior, both directly as a result of the program's activities, as well as indirectly through fostering the sort of social cohesion that is evidenced through higher expectations about peers' willingness to voluntarily cooperate for the social good. These effects could be partly

explained by the fact that a number of TARINA interventions were specifically targeted through existing and newly-formed village and self-help groups. Although there is not sufficient variation in the specific program components that different villages are exposed to that might contribute to these direct and indirect effects, the combined effect is nontrivial, and has important policy implications about the potential role for exogenous interventions to facilitate social cohesion and encourage pro-social behavior that could be beneficially leveraged for the effective management of myriad common property resources.

\section{Heterogeneity in effects leading to voluntary coop- eration}

In this section, we consider whether some of the determinants of voluntary cooperation analyzed in Table 2 have heterogeneous effects in our sample, based on several social domains, specifically gender and caste. For a number of reasons, largely tied up in religion and culture, women and members of scheduled castes and scheduled tribes have been historically disadvantaged within Indian society. Only relatively recently have groups like CARE-India made considerable investments in trying to improve upon this situation and empower these marginalized groups. Yet there remains little evidence whether these types of interventions have had differential effects on these groups. 


\subsection{Heterogeneous impacts by gender}

Since both TARINA and Pathways have primarily worked with women's self-help groups, it is worthwhile to examine whether women behave differently in the VCM when confronted with various sources of risk or varying group dynamics. In Table 4, columns (1)-(2), we report the results from regressing voluntary contributions on the determinants of contributions from Table 2, but in this case allowing for heterogeneity in the effect of risk (column [1]) or in the group composition (column[2]) based on the gender of the participant. In column (1), we find evidence that the effect of risk on voluntary cooperation is different for men and women. Whereas neither private risk nor public risk has an effect on the likelihood of voluntary cooperation among men in our sample, there are significant - and nearly diametrically opposed - effects of risk on the likelihood of women's voluntary cooperation. Specifically, much like we observed with the full sample on average, when there are risks in the returns to private activities, we find that women are 6.48 percentage points more likely to voluntarily contribute to the community good ( $p$-value of 0.005 ), despite remaining uncertainty about the returns to these cooperative contributions. When there is risk in the MPCR to voluntary contributions, which compounds the risk to cooperative contributions, our results suggest that women are 6.45 percentage points less likely to voluntarily contribute to the community good ( $p$-value of 0.005$)$.

We also consider whether there are differences in how group composition affects voluntary contributions between men and women. These results are reported in column (2) of Table 4. For men, being in mixed-sex groups in which there are unrelated men and women does not significantly affect the likelihood of voluntarily contributing to the community good, though there is some evidence that participating in mixed-sex groups with female members of the same household may increase men's cooperation (combined effect of $0.03, p$-value of 0.14 ). Group composition has considerably different effects on the likelihood of voluntary cooperation among women. In particular, women are 5.18 percentage points less likely to voluntary contribute ( $p$-value 0.003$)$ when they are in mixed-sex groups with unrelated men, and although being in groups with men from their own households, the mixed-sex nature of these groups implies they are still 5.18 percentage points less likely to cooperate 
( $p$-value of 0.02$)$.

\subsection{Heterogeneous impacts by caste}

In addition to working through women's self-help groups, both TARINA and Pathways have worked in areas that have relatively large concentrations of scheduled caste (SC) and scheduled tribe (ST) individuals, groups that have been historically marginalized. Because of their engagement with these groups, it is an empirical question whether these engagements have affected the social cohesion of these groups. In column (3) of Table 4, we report the results analyzing the determinants of voluntary contributions allowing for interactions between caste and village participation in TARINA and Pathways activities. Our results suggest that SC and ST households in TARINA villages demonstrate patterns of voluntary cooperation that are similar to SC and ST households in comparison villages ( $p$-values of 0.69 and 0.45 , respectively). Among households in Pathways villages, however, a different story emerges altogether. In these villages, SC households are about 19 percentage points less likely to voluntarily contribute ( $p$-value of 0.003$)$, while ST households are about 15 percentage points less likely to voluntarily contribute ( $p$-value of 0.01$)$. These impacts are quite striking, and perhaps indicative of a perverse impact of the types of livelihoods-based activities that Pathways is promoting. While CARE-India may intend to be providing beneficial empowerment to members of these traditionally marginalized communities, this may increase the salience of their past marginalization, which may, in turn, create a sense of resentment so these individuals may actually be less inclined toward voluntarily cooperating with members of general or other backwards castes $(\mathrm{OBC})$.

\section{Robustness check}

One potential area for concern in the interpretation of our results is the lingering potentiality that CARE's programming may have been targeted, and that this targeting may have been based on certain village-level characteristics. In particular, there may be unobservable characteristics that 
are correlated both with individuals' voluntary contributions to the community good as well as their villages being targeted for participation in either Pathways or TARINA activities (element $S$ in the DAG in Figure 1). If this is the case, then the estimated effects of Pathways and TARINA on these voluntary contributions would be biased. Given the rather stable and precise estimates for the effect of TARINA on voluntary contributions (especially after we control for expectations), we have fairly convincing evidence that there are no such unobserved factors associated with both TARINA and voluntary contributions, but we nevertheless want to allow for this potentiality and place some bounds on our estimated effects. To do so, we follow the approach introduced by Oster (2019). Oster (2019) has demonstrated that, if the relationship between the observed controls and the treatment is informative about the relationship between the unobserved controls and the treatment, one can calculate both a direct bias (due to omitted variables) and a bound on the coefficient of proportionality, $\delta$, that characterizes the information gleaned from the comparison of these relationships. These two calculations require some assumptions. The true $\delta$ is not known, nor can it be recovered directly, since by definition it is partly based on the relationship between the treatment and unobserved factors. Thus, we must make some assumptions about its value. To estimate the direct bias - or, more approporiately, to calculate the adjusted treatment effect - we can begin by assuming a $\delta=1$. We must also make an assumption about $R_{\max }$, which describes the goodness of model fit that could be obtained if we were able to control for all of the unobservable variables could be included in the regression. To put a bound on $\delta$, we can calculate the proportional degree of selection that would overturn our results (i.e., that would result in an estimated treatment effect of 0 ). To estimate the $\delta$ that would result in a reversal, we assume a treatment effect coefficient of zero, and make an assumption about $R_{\max }$. If we find estimates of $\delta>1$, this suggests that an omitted variable would have to be more correlated with the treatment variable than the current set of observables to produce a true treatment effect equal to zero (Sims and Alix-Garcia, 2017).

The results of this robustness check are reported in Table 5. The bias-adjusted effects for TARINA remain quite stable across specifications once we account for expectations, though as expected, these bias-adjusted effects are lower than reported in Table 2, suggesting that the estimated 
effects in Table 2 may be viewed as upper bounds on TARINA's effect on voluntary cooperation. More importantly, however, the estimated coefficients of proportionality $(\delta)$ that would be required to overturn the TARINA effects are all greater than one. Consequently, an omitted variable would have to be more highly correlated with the treatment variable than the current set of observables to produce a true null effect.

\section{Conclusion}

In this study we have used a voluntary contribution mechanism to study cooperation among members of remote rural communities in the eastern Indian state of Odisha. As in many remote rural communities, the communities in our sample are actively engaged in collectively managing myriad natural resources and other local common-pool resources for which neither private markets nor centralized government management emerge as viable governance strategies, either due to the nature of the resource or due to the remoteness of the communities and the ineffectiveness of external enforcement.

The experimental game was designed in such a way so that participants always face a social dilemma in which individuals' dominant strategy - retaining one's endowment for personal consumption - is socially inefficient. While rarely as stark as in this experimental setting, this type of social dilemma is a frequent occurrence in many rural contexts in developing countries, and thus this laboratory-in-field type of experiment provides a valuable lens into the decisionmaking dynamics of households confronted with these trade-offs.

With risk being a common - and increasing - presence in rural households' lives, we set out to see the extent to which cooperation in the management of community resources could be affected by the nature of risk. To do so, we followed the approach introduced in Cárdenas et al. (2017) and incorporated uncertainty into both the returns to private consumption as well as in the marginal per capita return to contributions in the community good in subsequent rounds of the voluntary contribution mechanism.

The results suggest that voluntary cooperation is far from perfect, even in a baseline scenario in 
which the only element of risk is in the extent of co-participants' cooperation in the voluntary contribution mechanism. Participants alter their strategies in subsequent rounds when additional risk is introduced, but the nature of the risk largely determines the nature of their adjustments. When the additional risk is constrained to the returns of private activities, there is an increased level of cooperation, whereas risk in the per capita returns to the community good crowds out cooperation. The composition of the group managing the community good is also an important determinant of cooperation. Contrary to what is often conjectured in the context of large-scale public goods which suggests a propensity for free-riding as the size of the population increases - and contrary to much of the literature on public goods games - which generally finds no evidence of size effects - we find that the propensity for cooperation actually increases with larger groups, perhaps suggesting that group members perceive the social optimality of broader cooperation compared to the social inefficiency of universal defection. Groups that are more homogeneous tend to favor greater levels of cooperation, as introducing gender diversity into groups reduces the level of cooperation, though this effect is partially offset with the gender mixing includes familial pairs.

We find strong evidence that expectations about co-participants cooperation is an important determinant of a participant's propensity toward cooperation. Both the level of these expectations as well as the manner in which these expectations translate into individual behavior seem as though they could both be influenced by external agents. Through mediation analysis, this study demonstrates that certain NGO programming can have both direct and indirect effects on cooperative behavior, with these indirect effects arising as the result of program impacts on participants' expectations of peer behavior. In particular, the results in the present study suggest that specific NGO activities - perhaps those that target social cohesion, cooperation, or resource management - could influence participants' expectations about the cooperativeness of their group members, as well as the manner in which these expectations are translated into one's own tendency to cooperate. Baseline levels of expectations about co-participants' behavior - before introducing additional elements of risk - are larger among households in villages that have benefitted from programming under the TARINA project, which entailed some elements arguably more centered around communitybuilding (e.g., improved animal husbandry, seed management, value chain linkages, storage, etc.). 
Consequently, the levels of cooperation in villages that have benefitted from TARINA programming are also higher, and the rate at which expectations are translated into voluntary contributions is higher than in villages that have been untouched by CARE's programming.

The policy implications of these findings are nontrivial: If it were possible - by the activities of some eternal actor like an NGO or other similar organization - to increase the level of social cohesion and raise awareness of the importance of cooperation in the management of common pool resources, then a virtuous cycle could be introduced leading to ever higher levels of cooperation and ever more effective local management of these resources. A question that remains, however, is what level of social cohesion could induce this sort of virtuous cycle? In other words, is there some threshold level of expectations beyond which the combination of unconditional and conditional cooperation would be so high as to ensure near universal cooperation in the management of these common pool resources. The identification of such a threshold and the exploration of the system dynamics that could result from external efforts to push social cohesion closer to this threshold should be a fruitful area of future research. 


\section{References}

Bagnoli, M. and B. Lipman (1989). Provision of public goods: Fully implementing the core through private contributions. Review of Economic Studies 56, 583-601.

Bardhan, P. (1993). Symposium on Management of Local Commons. The Journal of Economic Perspectives 7(4), 87-92.

Baron, R. M. and D. A. Kenny (1986). The moderator-mediator variable distinction in social psychological research: Conceptual, strategic, and statistical considerations. Journal of Personality and Social Psychology 51(6), 1173-1182.

Barr, A. (2001). Social dilemmas and shame-based sanctions: Experimental results from rural Zimbabwe. Working paper 2001.11, Centre for the Study of African Economies, Oxford University.

Bereby-Meyer, Y. and A. E. Roth (2006). The speed of learning in noisy games: Partial reinforcement and the sustainability of cooperation. American Economic Review 96(4), 1029-1042.

Beteille, A. (1983). Equality and inequality: Theory and practice. Delhi: Oxford University Press.

Brandts, J. and A. Schram (2001). Cooperation and noise in public goods experiments: Applying the contribution function approach. Journal of Public Economics 79(2), 399-427.

Cardenas, J. C. and J. Carpenter (2008). Behavioural development economics: Lessons from field labs in the developing world. Journal of Development Studies 44(3), 311-338.

Cárdenas, J.-C., M. A. Janssen, M. Ale, R. Bastakoti, A. Bernal, and J. Chalermphol (2017). Fragility of the provision of local public goods to private and collective risks. Proceedings of the National Academy of Sciences 114(5), 921-925.

Cardenas, J.-C., J. Stranlund, and C. Willis (2000). Local Environmental Control and Institutional Crowding-Out. World Development 28(10), 1719-1733. 
Cardenas, J. C., J. Stranlund, and C. Willis (2002). Economic inequality and burden-sharing in the provision of local environmental quality. Ecological Economics 40(3), 379-395.

Carpenter, J. P., A. G. Daniere, and L. M. Takahashi (2004). Social capital and trust in south-east Asian cities. Urban Studies 41(4), 853-874.

Croson, R. T. (2008). Public goods experiments. In S. N. Durlauf and L. E. Blume (Eds.), The New Palgrave Dictionary of Economics: Behavioral and experimental economics (2 ed.). New York: Palgrave Macmillan.

Cunningham, S. (2019). Causal inference: The mixtape. Available online: https://scunning.com/mixtape.html. Accessed 11/27/2019.: Mimeo.

Fischbacher, U., S. Gächter, and E. Fehr (2001). Are people conditionally cooperative? Evidence from a public goods experiment. Economics Letters 71(3), 397-404.

Hardin, G. (1968). The tragedy of the commons. Science 162, 1243-1248.

Isaac, R. M. and J. M. Walker (1988). Group Size Effects in Public Goods Provision: The Voluntary Contributions Mechanism. Quarterly Journal of Economics 103(1), 179-199.

Isaac, R. M., J. M. Walker, and S. H. Thomas (1984). Divergent expectations on free riding: An experimental examination of possible explanations. Public Choice 43, 113-149.

Karlan, D. S. (2005). Using Experimental Economics to Measure Social Capital and Predict Financial Decisions. American Economic Review 95(5), 1688-1699.

Kocher, M. G., P. Martinsson, D. Matzat, and C. Wollbrant (2015). The role of beliefs, trust, and risk in contributions to a public good. Journal of Economic Psychology 51, 236-244.

Meinzen-Dick, R., M. A. Janssen, S. Kandikuppa, R. Chaturvedi, K. Rao, and S. Theis (2018). Playing games to save water: Collective action games for groundwater management in Andhra Pradesh, India. World Development 10\%, 40-53. 
Morgan, S. and C. Winship (2010). Counterfactuals and causal inference. Cambridge University Press.

Offerman, T., J. Sonnermans, and A. Schram (1996). Value orientations, expectations and voluntary contributions in public goods. The Economic Journal 106, 817-845.

Oster, E. (2019). Unobservable selection and coefficient stability: Theory and evidence. Journal of Business and Economic Statistics 37(2), 187-204.

Ostrom, E. (1990). Governing the commons: The evolution of institutions for collective action. New York: Cambridge University Press.

Pearl, J. (2009). Causality: Models, reasoning, and inference. Cambridge University Press.

Pearl, J. and D. McKenzie (2018). The book of why. Penguin.

Seabright, P. (1993). Managing local commons: Theoretical issues in incentive design. Journal of Economic Perspectives 7(4), 113-134.

Sims, K. and J. Alix-Garcia (2017). Parks versus PES: Evaluating direct and incentive-based land conservation in Mexico. Journal of Environmental Economics and Management 86, 8-28.

Wade, R. (1987). The Management of Common Property Resources: Finding a Cooperative Solution. The World Bank Research Observer 2(2), 219-234.

Walker, J. M., R. Gardner, and E. Ostrom (1990). Rent Dissipation in a limited-access common-pool resource: Experimental evidence. Journal of Environmental Economics and Management 19, 203-211. 
Table 1: Descriptive statistics of sample households

\begin{tabular}{|c|c|c|c|c|c|c|c|}
\hline Characteristic & $\begin{array}{c}(1) \\
\text { Full } \\
\text { sample }\end{array}$ & $\begin{array}{c}(2) \\
\text { TARINA } \\
\text { villages }\end{array}$ & $\begin{array}{c}(3) \\
\text { Pathways } \\
\text { villages }\end{array}$ & $\begin{array}{c}(4) \\
\text { Comparison } \\
\text { villages }\end{array}$ & $\begin{array}{c}(5) \\
\text { TARINA - } \\
\text { Pathways }\end{array}$ & $\begin{array}{c}(6) \\
\text { TARINA - } \\
\text { Comparison }\end{array}$ & $\begin{array}{c}(7) \\
\text { Pathways - } \\
\text { Comparison }\end{array}$ \\
\hline Age (years) & $\begin{array}{l}41.999 \\
(0.337)\end{array}$ & $\begin{array}{l}43.590 \\
(0.655)\end{array}$ & $\begin{array}{l}41.655 \\
(0.466)\end{array}$ & $\begin{array}{l}41.801 \\
(0.526)\end{array}$ & $\begin{array}{c}1.935 \\
{[0.016]}\end{array}$ & $\begin{array}{c}1.789 \\
{[0.033]}\end{array}$ & $\begin{array}{c}-0.146 \\
{[0.835]}\end{array}$ \\
\hline Gender $($ woman $=1)$ & $\begin{array}{c}0.504 \\
(0.012)\end{array}$ & $\begin{array}{c}0.509 \\
(0.025)\end{array}$ & $\begin{array}{c}0.499 \\
(0.019)\end{array}$ & $\begin{array}{l}0.506 \\
(0.017)\end{array}$ & $\begin{array}{c}0.010 \\
{[0.808]}\end{array}$ & $\begin{array}{c}0.003 \\
{[0.609]}\end{array}$ & $\begin{array}{c}-0.006 \\
{[0.797]}\end{array}$ \\
\hline Religion $($ Hindu $=1)$ & $\begin{array}{c}0.953 \\
(0.005)\end{array}$ & $\begin{array}{c}0.901 \\
(0.015)\end{array}$ & $\begin{array}{c}0.956 \\
(0.008)\end{array}$ & $\begin{array}{l}0.970 \\
(0.006)\end{array}$ & $\begin{array}{c}-0.054 \\
{[0.001]}\end{array}$ & $\begin{array}{r}-0.069 \\
{[0.010]}\end{array}$ & $\begin{array}{c}-0.014 \\
{[0.299]}\end{array}$ \\
\hline Marital status $($ married $=1)$ & $\begin{array}{c}0.957 \\
(0.005)\end{array}$ & $\begin{array}{c}0.957 \\
(0.010)\end{array}$ & $\begin{array}{c}0.961 \\
(0.007)\end{array}$ & $\begin{array}{l}0.950 \\
(0.007)\end{array}$ & $\begin{array}{c}-0.004 \\
{[0.855]}\end{array}$ & $\begin{array}{c}0.007 \\
{[0.037]}\end{array}$ & $\begin{array}{l}0.011 \\
{[0.002]}\end{array}$ \\
\hline Literacy $($ literate $=1$ ) & $\begin{array}{c}0.528 \\
(0.012)\end{array}$ & $\begin{array}{c}0.539 \\
(0.025)\end{array}$ & $\begin{array}{c}0.556 \\
(0.019)\end{array}$ & $\begin{array}{c}0.512 \\
(0.017)\end{array}$ & $\begin{array}{c}-0.017 \\
{[0.631]}\end{array}$ & $\begin{array}{l}0.028 \\
{[0.183]}\end{array}$ & $\begin{array}{l}0.045 \\
{[0.021]}\end{array}$ \\
\hline Household head $($ head $=1)$ & $\begin{array}{c}0.484 \\
(0.012)\end{array}$ & $\begin{array}{c}0.473 \\
(0.025)\end{array}$ & $\begin{array}{c}0.494 \\
(0.019)\end{array}$ & $\begin{array}{c}0.479 \\
(0.017)\end{array}$ & $\begin{array}{r}-0.020 \\
{[0.557]}\end{array}$ & $\begin{array}{c}-0.006 \\
{[0.849]}\end{array}$ & $\begin{array}{c}0.014 \\
{[0.286]}\end{array}$ \\
\hline Household size & $\begin{array}{c}5.363 \\
(0.049)\end{array}$ & $\begin{array}{c}5.159 \\
(0.097)\end{array}$ & $\begin{array}{c}5.302 \\
(0.070)\end{array}$ & $\begin{array}{c}5.433 \\
(0.075)\end{array}$ & $\begin{array}{c}-0.143 \\
{[0.234]}\end{array}$ & $\begin{array}{c}-0.274 \\
{[0.026]}\end{array}$ & $\begin{array}{c}-0.131 \\
{[0.205]}\end{array}$ \\
\hline \multicolumn{8}{|l|}{ Risk preferences } \\
\hline Very risk averse & $\begin{array}{c}0.135 \\
(0.008)\end{array}$ & $\begin{array}{c}0.147 \\
(0.018)\end{array}$ & $\begin{array}{c}0.122 \\
(0.012)\end{array}$ & $\begin{array}{c}0.139 \\
(0.012)\end{array}$ & $\begin{array}{c}0.025 \\
{[0.280]}\end{array}$ & $\begin{array}{c}0.007 \\
{[0.649]}\end{array}$ & $\begin{array}{c}-0.017 \\
{[0.468]}\end{array}$ \\
\hline Moderately risk averse & $\begin{array}{c}0.345 \\
(0.011)\end{array}$ & $\begin{array}{c}0.339 \\
(0.024)\end{array}$ & $\begin{array}{c}0.359 \\
(0.018)\end{array}$ & $\begin{array}{c}0.343 \\
(0.016)\end{array}$ & $\begin{array}{c}-0.020 \\
{[0.547]}\end{array}$ & $\begin{array}{c}-0.004 \\
{[0.897]}\end{array}$ & $\begin{array}{c}0.016 \\
{[0.308]}\end{array}$ \\
\hline Risk neutral & $\begin{array}{c}0.205 \\
(0.010)\end{array}$ & $\begin{array}{c}0.258 \\
(0.022)\end{array}$ & $\begin{array}{c}0.229 \\
(0.016)\end{array}$ & $\begin{array}{c}0.174 \\
(0.013)\end{array}$ & $\begin{array}{c}0.029 \\
{[0.305]}\end{array}$ & $\begin{array}{c}0.084 \\
{[0.000]}\end{array}$ & $\begin{array}{c}0.055 \\
{[0.003]}\end{array}$ \\
\hline Moderately risk loving & $\begin{array}{c}0.080 \\
(0.006)\end{array}$ & $\begin{array}{c}0.068 \\
(0.013)\end{array}$ & $\begin{array}{c}0.074 \\
(0.010)\end{array}$ & $\begin{array}{c}0.084 \\
(0.009)\end{array}$ & $\begin{array}{c}-0.005 \\
{[0.843]}\end{array}$ & $\begin{array}{c}-0.016 \\
{[0.474]}\end{array}$ & $\begin{array}{c}-0.011 \\
{[0.603]}\end{array}$ \\
\hline Very risk loving & $\begin{array}{c}0.236 \\
(0.010)\end{array}$ & $\begin{array}{c}0.187 \\
(0.020)\end{array}$ & $\begin{array}{c}0.216 \\
(0.015)\end{array}$ & $\begin{array}{c}0.259 \\
(0.015)\end{array}$ & $\begin{array}{c}-0.029 \\
{[0.285]}\end{array}$ & $\begin{array}{c}-0.072 \\
{[0.014]}\end{array}$ & $\begin{array}{c}-0.043 \\
{[0.106]}\end{array}$ \\
\hline \multicolumn{8}{|l|}{ Caste } \\
\hline General caste & $\begin{array}{c}0.029 \\
(0.004)\end{array}$ & $\begin{array}{c}0.035 \\
(0.009)\end{array}$ & $\begin{array}{c}0.036 \\
(0.007)\end{array}$ & $\begin{array}{c}0.020 \\
(0.005)\end{array}$ & $\begin{array}{c}-0.001 \\
{[1.000]}\end{array}$ & $\begin{array}{c}0.016 \\
{[0.115]}\end{array}$ & $\begin{array}{c}0.016 \\
{[0.050]}\end{array}$ \\
\hline Other backward caste (OBC) & $\begin{array}{c}0.186 \\
(0.009)\end{array}$ & $\begin{array}{c}0.159 \\
(0.018)\end{array}$ & $\begin{array}{c}0.110 \\
(0.012)\end{array}$ & $\begin{array}{c}0.243 \\
(0.015)\end{array}$ & $\begin{array}{c}0.050 \\
{[0.021]}\end{array}$ & $\begin{array}{c}-0.084 \\
{[0.002]}\end{array}$ & $\begin{array}{c}-0.134 \\
{[0.000]}\end{array}$ \\
\hline Scheduled caste (SC) & $\begin{array}{c}0.204 \\
(0.010)\end{array}$ & $\begin{array}{c}0.162 \\
(0.019)\end{array}$ & $\begin{array}{c}0.251 \\
(0.016)\end{array}$ & $\begin{array}{c}0.171 \\
(0.013)\end{array}$ & $\begin{array}{c}-0.089 \\
{[0.001]}\end{array}$ & $\begin{array}{c}-0.008 \\
{[0.933]}\end{array}$ & $\begin{array}{l}0.081 \\
{[0.000]}\end{array}$ \\
\hline Scheduled tribe (ST) & $\begin{array}{c}0.581 \\
(0.012)\end{array}$ & $\begin{array}{c}0.643 \\
(0.024)\end{array}$ & $\begin{array}{c}0.603 \\
(0.018)\end{array}$ & $\begin{array}{c}0.567 \\
(0.017)\end{array}$ & $\begin{array}{c}0.040 \\
{[0.215]}\end{array}$ & $\begin{array}{c}0.076 \\
{[0.002]}\end{array}$ & $\begin{array}{c}0.037 \\
{[0.039]}\end{array}$ \\
\hline Total income (avg per month) & $\begin{array}{r}3659.011 \\
(66.237)\end{array}$ & $\begin{array}{l}3681.013 \\
(145.859)\end{array}$ & $\begin{array}{r}3498.110 \\
(98.143)\end{array}$ & $\begin{array}{r}3781.381 \\
(95.531)\end{array}$ & $\begin{array}{r}182.903 \\
{[0.298]}\end{array}$ & $\begin{array}{r}-100.369 \\
{[0.565]}\end{array}$ & $\begin{array}{r}-283.272 \\
{[0.039]}\end{array}$ \\
\hline Household has access to irrigation $(=1)$ & $\begin{array}{c}0.260 \\
(0.010)\end{array}$ & $\begin{array}{c}0.256 \\
(0.022)\end{array}$ & $\begin{array}{c}0.239 \\
(0.016)\end{array}$ & $\begin{array}{c}0.265 \\
(0.015)\end{array}$ & $\begin{array}{c}0.017 \\
{[0.573]}\end{array}$ & $\begin{array}{c}-0.009 \\
{[0.999]}\end{array}$ & $\begin{array}{c}-0.026 \\
{[0.412]}\end{array}$ \\
\hline Proportion contributing in baseline round & $\begin{array}{c}0.43 \\
(0.49)\end{array}$ & $\begin{array}{c}0.52 \\
(0.50)\end{array}$ & $\begin{array}{c}0.45 \\
(0.50)\end{array}$ & $\begin{array}{c}0.40 \\
(0.49)\end{array}$ & & & \\
\hline Proportion contributing in private risk round & $\begin{array}{c}0.48 \\
(0.50)\end{array}$ & $\begin{array}{c}0.54 \\
(0.50)\end{array}$ & $\begin{array}{c}0.47 \\
(0.50)\end{array}$ & $\begin{array}{c}0.47 \\
(0.50)\end{array}$ & & & \\
\hline Proportion contributing in collective risk round & $\begin{array}{c}0.41 \\
(0.49) \\
\end{array}$ & $\begin{array}{c}0.46 \\
(0.50) \\
\end{array}$ & $\begin{array}{c}0.42 \\
(0.49) \\
\end{array}$ & $\begin{array}{c}0.39 \\
(0.49) \\
\end{array}$ & & & \\
\hline & 1761 & 395 & 721 & 868 & & & \\
\hline
\end{tabular}

Source: Authors.

Notes: In columns (1)-(4), standard errors of sub-sample means or proportions (in the case of binary characteristics) in appear in parentheses. In columns (5) - (7), p-values from tests of equal sub-sample means or proportions reported in brackets. Sum of sub-sample sizes exceeds total number of observations because some villages were recipients of both Pathways and TARINA programming. 


\section{Table 2: Determinants of contributions to community good}

\begin{tabular}{|c|c|c|c|c|c|}
\hline Dependent variable: voluntary contributions to community fund & $(1)$ & $(2)$ & $(3)$ & $(4)$ & $(5)$ \\
\hline Village participated in TARINA & $\begin{array}{c}0.064 \\
(3.143)\end{array}$ & $\begin{array}{c}0.050 \\
(2.535)\end{array}$ & $\begin{array}{c}0.050 \\
(2.537)\end{array}$ & $\begin{array}{c}0.047 \\
(2.391)\end{array}$ & $\begin{array}{c}0.047 \\
(2.415)\end{array}$ \\
\hline Village participated in Pathways & $\begin{array}{c}-0.013 \\
(-0.758)\end{array}$ & $\begin{array}{c}-0.006 \\
(-0.362)\end{array}$ & $\begin{array}{c}-0.006 \\
(-0.363)\end{array}$ & $\begin{array}{c}-0.010 \\
(-0.603)\end{array}$ & $\begin{array}{c}-0.003 \\
(-0.155)\end{array}$ \\
\hline Expected proportion of cooperators & & $\begin{array}{c}0.364 \\
(11.307)\end{array}$ & $\begin{array}{c}0.363 \\
(11.279)\end{array}$ & $\begin{array}{c}0.383 \\
(11.860)\end{array}$ & $\begin{array}{c}0.363 \\
(11.287)\end{array}$ \\
\hline Risk in returns to private activity & & & $\begin{array}{c}0.042 \\
(2.909)\end{array}$ & $\begin{array}{c}0.041 \\
(2.882)\end{array}$ & $\begin{array}{c}0.042 \\
(2.908)\end{array}$ \\
\hline Risk in returns to community contributions & & & $\begin{array}{c}-0.024 \\
(-1.688)\end{array}$ & $\begin{array}{c}-0.024 \\
(-1.711)\end{array}$ & $\begin{array}{c}-0.024 \\
(-1.688)\end{array}$ \\
\hline Group size & & & & $\begin{array}{c}0.011 \\
(3.804)\end{array}$ & \\
\hline Group composition: mixed-sex & & & & & $\begin{array}{c}-0.040 \\
(-2.038)\end{array}$ \\
\hline Group composition: mixed-sex, same household & & & & & $\begin{array}{c}0.031 \\
(1.618)\end{array}$ \\
\hline Total number of observations & 5283 & 5283 & 5283 & 5283 & 5283 \\
\hline Number of individuals & 1761 & 1761 & 1761 & 1761 & 1761 \\
\hline$R^{2}$ & 0.03 & 0.06 & 0.06 & 0.07 & 0.07 \\
\hline
\end{tabular}

Source: Authors.

Notes: $t$-statistics computed using standard errors adjusted for individual-level clustering in parentheses. In each regression, the dependent variable is a binary indicator for contribution to the community good. All regressions contain additional controls for age, gender (binary), caste (OBC, SC, and ST binaries), religion (Hindu binary variable), marital status, household size, total household incoe, status as household head, literacy, risk preferences, and district fixed effects. 
Table 3: Mediation analysis: The role of NGO programs and game characteristics on participants' expectations about peers' contributions to community good

\begin{tabular}{|c|c|c|c|}
\hline Dependent variable: expectations of peers' voluntary cooperations (proportion) & $(1)$ & $(2)$ & $(3)$ \\
\hline Village participated in TARINA & $\begin{array}{c}0.039 \\
(3.385)\end{array}$ & $\begin{array}{c}0.039 \\
(3.384)\end{array}$ & $\begin{array}{c}0.051 \\
(3.619)\end{array}$ \\
\hline Village participated in Pathways & $\begin{array}{c}-0.019 \\
(-1.953)\end{array}$ & $\begin{array}{c}-0.019 \\
(-1.953)\end{array}$ & $\begin{array}{c}-0.025 \\
(-2.099)\end{array}$ \\
\hline Risk in returns to private activity & & $\begin{array}{c}0.018 \\
(3.024)\end{array}$ & $\begin{array}{r}0.015 \\
(1.953)\end{array}$ \\
\hline Risk in returns to community contributions & & $\begin{array}{c}0.016 \\
(2.787)\end{array}$ & $\begin{array}{c}0.019 \\
(2.491)\end{array}$ \\
\hline TARINA $\times$ Risk in returns to private activity & & & $\begin{array}{c}-0.021 \\
(-1.451)\end{array}$ \\
\hline TARINA $\times$ Risk in returns to community contributions & & & $\begin{array}{c}-0.016 \\
(-1.131)\end{array}$ \\
\hline Pathways $\times$ Risk in returns to private activity & & & $\begin{array}{c}0.017 \\
(1.442)\end{array}$ \\
\hline Pathways $\times$ Risk in returns to community contributions & & & $\begin{array}{c}0.002 \\
(0.154) \\
\end{array}$ \\
\hline Total number of observations & 5283 & 5283 & 5283 \\
\hline Number of individuals & 1761 & 1761 & 1761 \\
\hline$R^{2}$ & 0.05 & 0.05 & 0.05 \\
\hline
\end{tabular}

Source: Authors.

Notes: $t$-statistics computed using standard errors adjusted for individual-level clustering in parentheses. In each regression, the dependent variable is the expected proportion of peers' contributions to the community good in voluntary contribution games. All regressions contain additional controls for age, gender (binary), caste (OBC, SC, and ST binaries), religion (Hindu binary variable), marital status, household size, total household incoe, status as household head, literacy, risk preferences, and district fixed effects. 
Table 4: Heterogeneity in determinants of contributions to community good

\begin{tabular}{|c|c|c|c|}
\hline Dependent variable: voluntary contributions to community fund & (1) & $(2)$ & (3) \\
\hline Participant is a woman & $\begin{array}{l}0.005 \\
(0.096)\end{array}$ & $\begin{array}{c}0.037 \\
(0.662)\end{array}$ & $\begin{array}{l}-0.007 \\
(-0.126)\end{array}$ \\
\hline Risk in returns to private activity & $\begin{array}{c}0.019 \\
(0.890)\end{array}$ & & \\
\hline Risk in returns to community contributions & $\begin{array}{c}0.017 \\
(0.851)\end{array}$ & & \\
\hline Participant is a woman $\times$ Risk in returns to private activity & $\begin{array}{l}0.046 \\
(1.610)\end{array}$ & & \\
\hline Participant is a woman $\times$ Risk in returns to community contributions & $\begin{array}{l}-0.081 \\
(-2.853)\end{array}$ & & \\
\hline Group composition: mixed-sex & & $\begin{array}{l}-0.011 \\
(-0.375)\end{array}$ & \\
\hline Group composition: mixed-sex, same household & & $\begin{array}{c}0.045 \\
(1.620)\end{array}$ & \\
\hline Participant is a woman $\times$ Group composition: mixed-sex & & $\begin{array}{l}-0.057 \\
(-1.481)\end{array}$ & \\
\hline Participant is a woman $\times$ Group composition: mixed-sex, same household & & $\begin{array}{l}-0.028 \\
(-0.760)\end{array}$ & \\
\hline Village participated in TARINA & & & $\begin{array}{c}0.130 \\
(1.433)\end{array}$ \\
\hline Village participated in Pathways & & & $\begin{array}{l}0.157 \\
(1.811)\end{array}$ \\
\hline Participant is from Scheduled Caste (SC) & & & $\begin{array}{l}0.006 \\
(0.081)\end{array}$ \\
\hline Participant is from Scheduled Tribe (ST) & & & $\begin{array}{c}0.014 \\
(0.189)\end{array}$ \\
\hline Participant is from Scheduled Caste $(\mathrm{SC}) \times$ Village participated in TARINA & & & $\begin{array}{l}-0.042 \\
(-0.413)\end{array}$ \\
\hline Participant is from Scheduled Tribe $(\mathrm{ST}) \times$ Village participated in TARINA & & & $\begin{array}{l}-0.078 \\
(-0.830)\end{array}$ \\
\hline Participant is from Scheduled Caste $(\mathrm{SC}) \times$ Village participated in Pathways & & & $\begin{array}{l}-0.196 \\
(-2.106)\end{array}$ \\
\hline Participant is from Scheduled Tribe $(\mathrm{ST}) \times$ Village participated in Pathways & & & $\begin{array}{c}-0.168 \\
(-1.890) \\
\end{array}$ \\
\hline Total number of observ & 5283 & 5283 & 5283 \\
\hline Number of individuals & 1761 & 1761 & 1761 \\
\hline$R^{2}$ & 0.07 & 0.07 & 0.07 \\
\hline
\end{tabular}

Source: Authors.

Notes: $t$-statistics computed using standard errors adjusted for individual-level clustering in parentheses. In each regression, the dependent variable is a binary indicator for contribution to the community good. All regressions contain additional controls for age, OBC caste (binary variable), religion (Hindu binary variable), marital status, household size, total household income, status as household head, literacy, risk preferences, the expected cooperation of peers in the group, group size, and district fixed effects. 
Table 5: Tests for stability of treatment effects estimates

\begin{tabular}{lccccc}
\hline Outcomes & $(1)$ & $(2)$ & $(3)$ & $(4)$ & $(5)$ \\
\hline Village participated in TARINA & 0.064 & 0.050 & 0.050 & 0.047 & 0.047 \\
& $(3.143)$ & $(2.535)$ & $(2.537)$ & $(2.391)$ & $(2.415)$ \\
Bias-adjusted $\beta$ & 0.053 & 0.035 & 0.035 & 0.031 & 0.032 \\
$\delta$ required to overturn results & 4.282 & 2.948 & 2.966 & 2.648 & 2.695 \\
\hline Village participated in Pathways & -0.013 & -0.006 & -0.006 & -0.010 & -0.003 \\
& $(-0.758)$ & $(-0.362)$ & $(-0.363)$ & $(-0.603)$ & $(-0.155)$ \\
Bias-adjusted $\beta$ & -0.022 & -0.013 & -0.013 & -0.018 & -0.008 \\
$\delta$ required to overturn results & -1.467 & -0.911 & -0.912 & -1.273 & -0.461 \\
\hline
\end{tabular}

Source: Authors.

Notes: In the first two rows of each panel, we replicate the results from the regressions in columns (1)(5) in Table 2, with $t$-statistics computed using standard errors adjusted for individual-level clustering in parentheses. $\beta$ estimates indicate the treatment effect that is implied by a coefficient of proportionality $(\delta)$ equal to one and $R_{\max }$ equal to 1.3 times the $R^{2}$ from the intial regressions reported in Table 2 , and the subsequent estimates for $\delta$ provide the coefficient of proportionality needed to result in treatment effects equal to zero under the same assumed value for $R_{\max }$. 


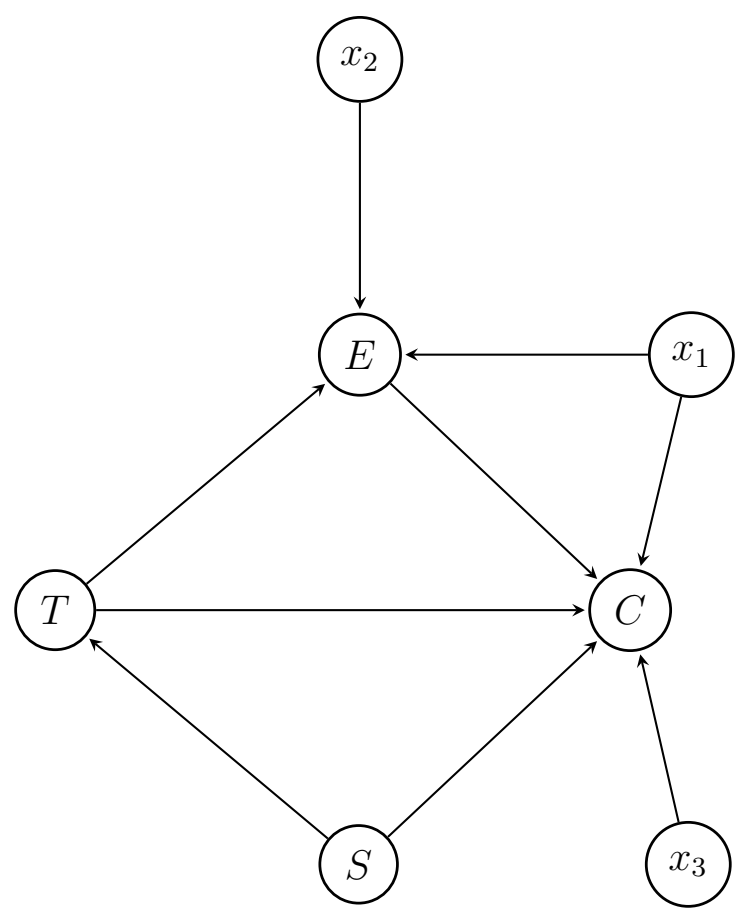

Figure 1: Directed acyclic graph (DAG) depicting causal pathway between participation in NGO programs $(T)$ and cooperation in the management of common property resources $(C)$ Source: The authors. 


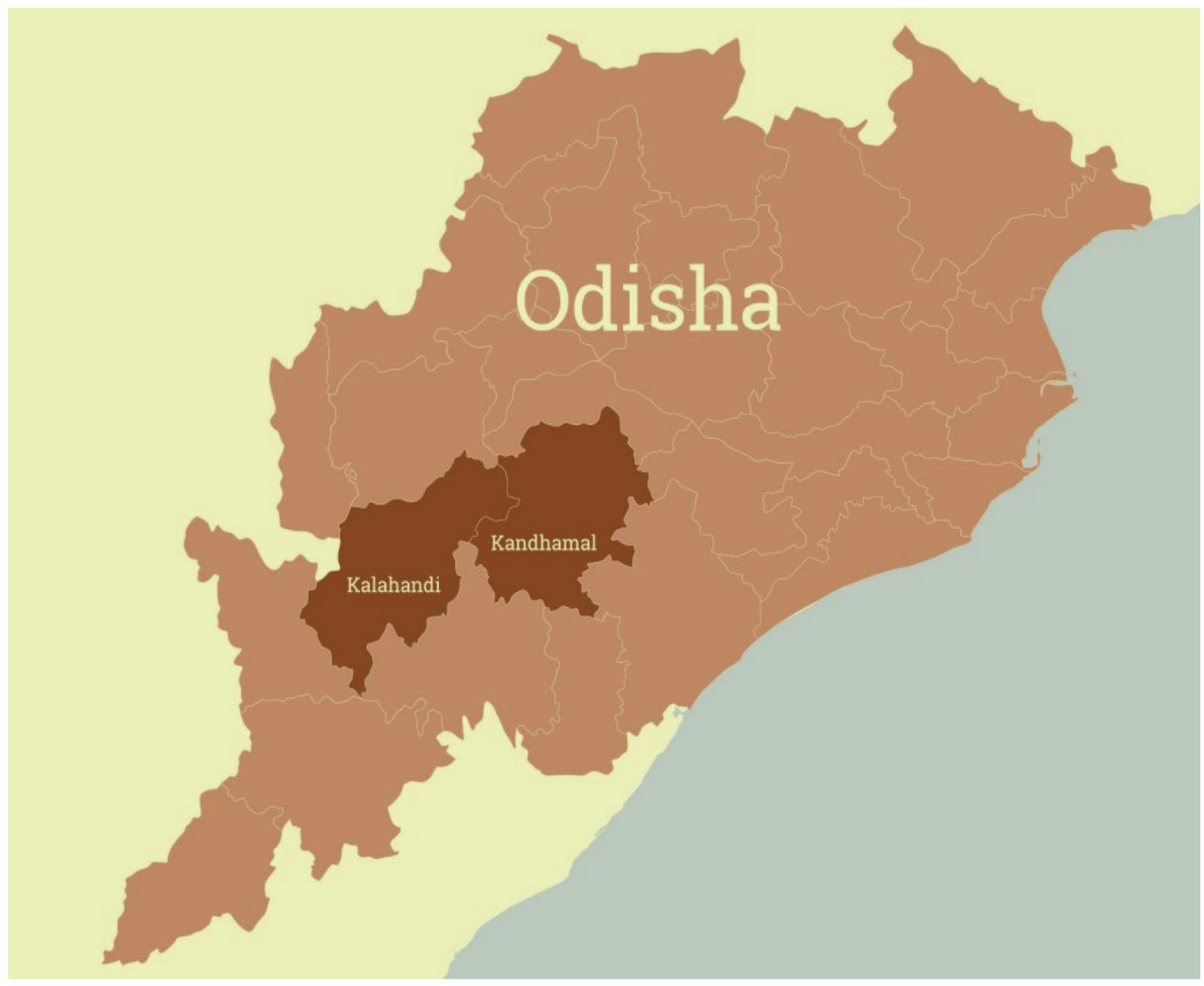

Figure 2: Location of sample districts, Odisha state, India 


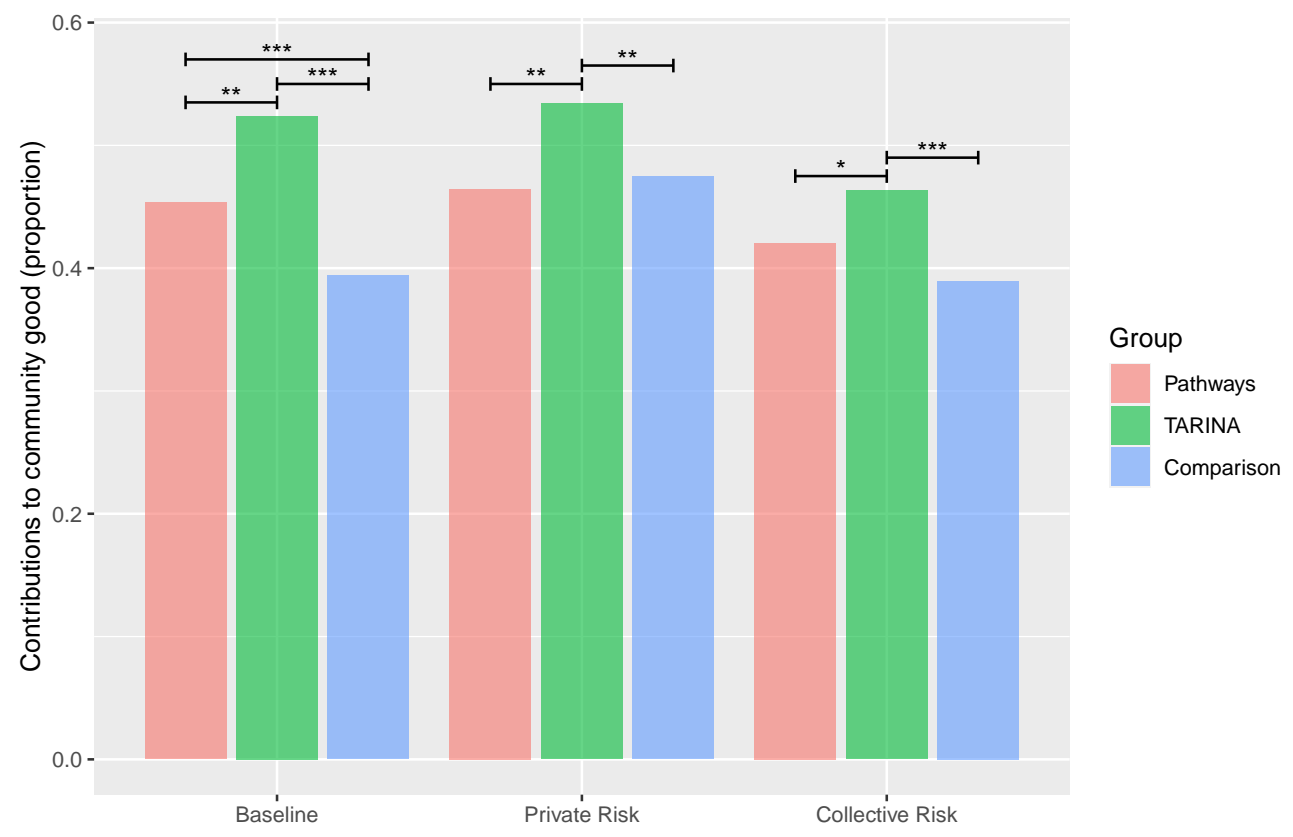

Figure 3: Contributions to the community good, by round and treatment Source: The authors. Note: ${ }^{* * *} p \leq 0.01 ;{ }^{* *} 0.01<p \leq 0.05 ;{ }^{*} 0.05<p \leq 0.1$. 


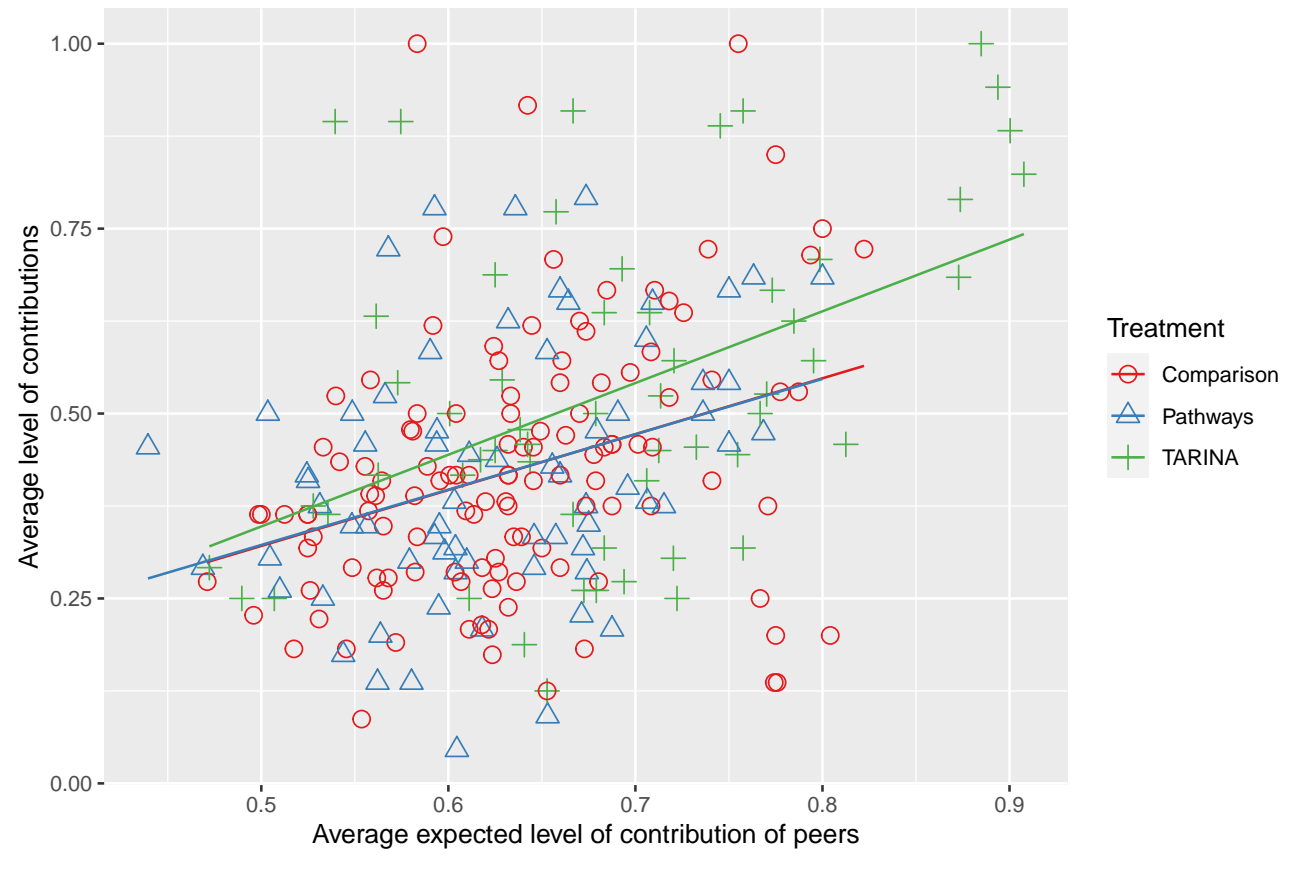

Figure 4: Contributions to the community good and expectations of co-participants' contributions the community good, by treatment

Source: The authors. Note: The linear regressions for Pathways and comparison villages have nearly identical slope coefficients ( 0.748 and 0.756 , respectively). Consequently, the plotted regression lines are virtually indistinguishable. 


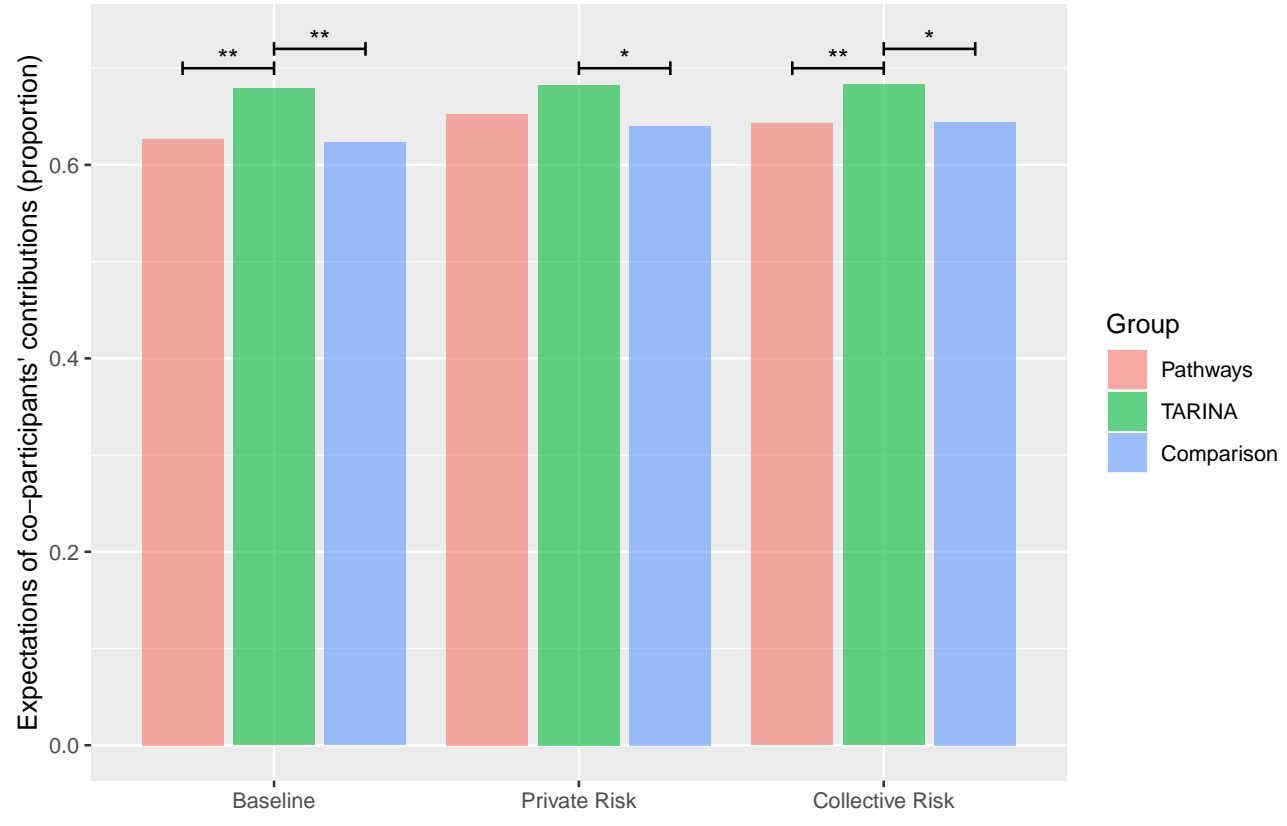

Figure 5: Expectations of co-participants' contributions the community good, by round and treatment

Source: The authors. Note: ${ }^{* * *} p \leq 0.01$; $^{* *} 0.01<p \leq 0.05 ;{ }^{*} 0.05<p \leq 0.1$. 


\section{ALL IFPRI DISCUSSION PAPERS}

All discussion papers are available here

They can be downloaded free of charge

INTERNATIONAL FOOD POLICY RESEARCH INSTITUTE

www.ifpri.org

\section{IFPRI HEADQUARTERS}

1201 Eye Street, NW

Washington, DC 20005 USA

Tel.: +1-202-862-5600

Fax: +1-202-862-5606

Email: ifpri@cgiar.org 